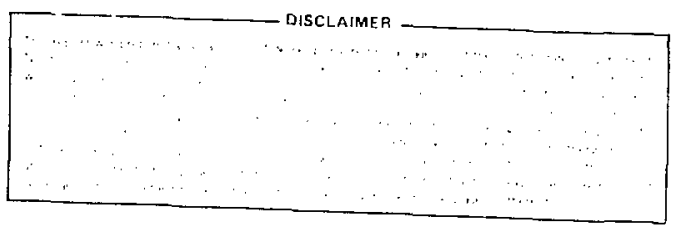

\title{
Postclosure Risks of Alternative SRP Nuclear Waste Forms in Geologic Repositories
}

\author{
H. Cheung \\ L. Edwards \\ T. Harvey \\ M. Revelli
}

Manuscript date: May 1982

\section{LAWRENCE LIVERMORE LABORATORY} University of California 1 I ivermore, California $\bullet 94550$ 


\section{Contents}

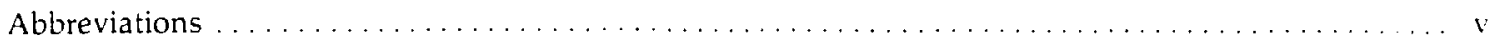

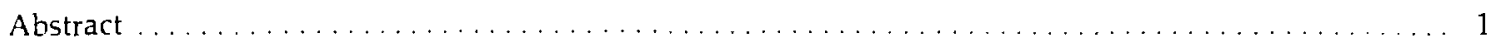

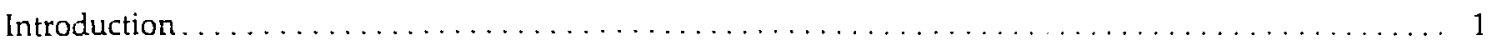

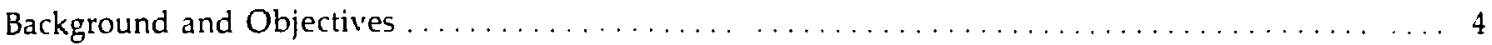

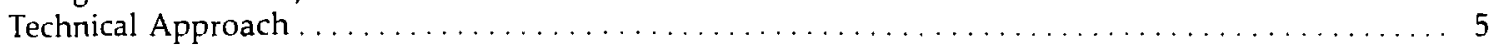

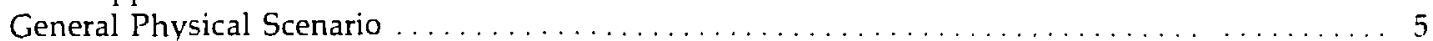

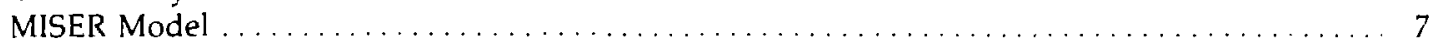

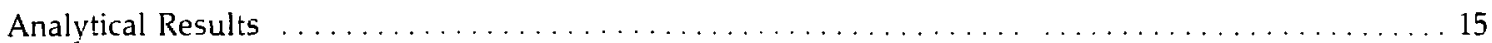

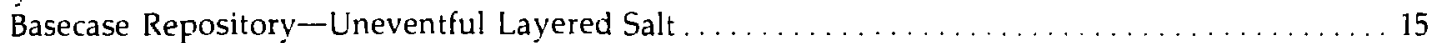

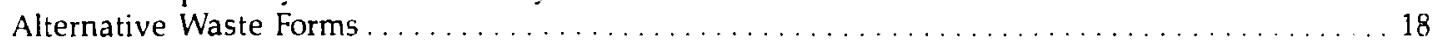

Release Rates and Uncertainties . . . . . . . . . . . . . . . . . . . . . . . . 32

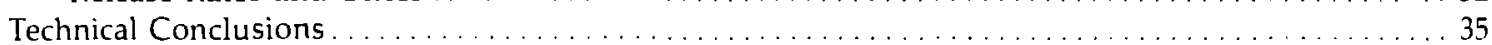

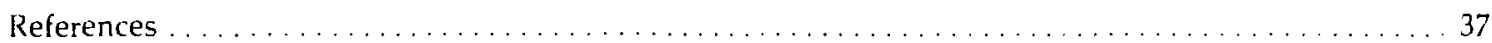




\section{ABBREVIATIONS}

AEI

ALI

BE

CRI

CRP4

CRP5

CRP6

DOE

DWPF

EIS

HLW

ICRP30

LI

MISER

NEPA

SRL

SRP

10CFR20

10 CFR 50

40CFR 191

$30 \mathrm{CL}$

$70 \mathrm{CL}$

$90 \mathrm{CL}$

$95 \mathrm{CL}$
Accessible environment individual

Annual limit of intake

Best estimate

Columbia River individual

Columbia River population integrated for $10^{4} y$

Same as CRP4 except integrated for $10^{5} \mathrm{y}$

Same as CRP4 except integrated for $10^{6} y$

Department of Energy

Defense waste processing facility

Environmental Impact Statement

High-level waste

International Commission on Radiation Protection, Publiration 30

Limiting Individual

Mine Scale Risk Assessment Code

National Environmental Protection Act

Savannah River Laboratory

Savannah River Plant

iitle 10, Code of Federal Regulations, Part 20

Same as 10CFR20, but Part 50

Title 40, Code of Federal Regulations, Part 191

$30 \%$ confidence level

$70 \%$ confidence level

$90 \%$ confidence level

$95 \%$ confidence level 


\title{
Postclosure Risks of Alternative SRP Nuclear Waste Forms in Geologic Repositories
}

\begin{abstract}
The postclosure risks of REFERENCE and ALTERNATIVE waste forms for the defense high-level waste at the Savannah River Plant (SRP) were compared by analyses with a computer code, MISER, written to study the effects of repository features in a probabilistic framework. MISER traces radionuclide flows through a network of stream tubes from the repository to risk-sensitive points. Uncertainties in waste form, package properties, and geotechnical data are accounted for with Monte Carlo techniques. Our results show: 1) for generic layered-salt and basalt repositories, the difference in performance between the two waste forms is insignificant; 2) where the doses are sensitive to uncertainties in leaching rates, the doses are orders of magnitude below background; 3 ) disruptive events contribute only slightly to the risk of a layered-salt repository; 4) simple design alterations have strong effects on near field doses; 5) great care should be exercised in selecting the location at which repository risks are to be measured, calculated, or regulated.
\end{abstract}

\section{Introduction}

Significant quantities of defense nuclear high-level waste (HLW) have been accumulated in defense programs at SRP. To immobilize these wastes for permanent disposal in a Federal Repository, SRP is developing a nuclear defense waste processing facility (DWPF). Borosilicate glass is the reference waste form and a crystalline ceramic form, SYNROC, is the primary alternative for the immobilization of SRP waste in the DWWP. This report for SRP is designed to frovide timely, state-of-the-art scientific information on the longterm risks of disposing of defense HLW in solid waste forms in bedded salt and other geologic repositories. Technical data to satisfy NEPA needs for an evaluation of the waste form alternatives requires development of a model that predicts not only individual dose, but also population dose associated with an extensive water use system.

\section{Technical Approach}

The most probable process for release of significant quantities of radionuclides to the human environment from a closed, deep geologic nuclear repository is leach of the waste form and ground- water transport.' The process involves a scenario that allows ground water to come into contact with the waste, leach the radionuclides, and transport them to the human environment. To provide a scientific analysis, we must deal not only with the complexity of the phenomena, but also with uncertainties inherent in the processes and in extrapolation of data over extended periods. Although it may introduce additional uncertainties, computer modeling is a necessary means to quantitatively forecast the behavior of radionuclides in repositories. The MISER code ${ }^{2}$ was written to study efficiently the effects of repository system design in a probabilistic framework in both the near-field and far-field. MISER is written in a modular fashion to allow rapid implementation of new or improved models. It is user orieited and generates exiensive graphical output. MISER computes radiation dosages to man at risk-sensitive observation points. Monte Carlo techniques are applied where appropriate to account for parameter uncertainties and correlations.

The MISER model can be conceived of as a combination of four numerical submodels:

- Waste Package Model. This model describes the radionuclides originally in the canister 
and their release as a function of time to the surrounding excavation. The original amount of radionuclides in a canister, a nonstochastic (certain) quantity in this analysis, is used to calculate the set of radionuclides as a function of time in the system. Thus, the total amount of radioactivity in the total system is certain. Its spacial distribution as a function of time is uncertain, however. Conservative assumptions were made in deriving a waste form release rate for the basecase analysis.

- Hydrology Model. This model consists of a defined network and of parameters describing the flow paths, the locations of the source canisters and of the monitor points. Under simplifying assumptions, we solve the steady state hydrology using Darcy's law and the conservation of water.

- Transport Model. This computes the radionuclides transported as a function of time and position. Thousands of radionuclide flux pulses can be transported. These are accumulated over time and converted to dose.

- Biological Pathways Model. To provide a spectrum of results compatible with today's regulations we emphasize two sets of results: those for an individual drinking from a well at the edge of the "accessible environment," which we call the accessible environment-individual ( $A E I$ ) model, and a population dose model for the current Columbia River water-use system-the Columbia River population (CRP) model.

\section{Techrical Results and Conclusions}

Our approach is to focus on a "basecase" scenario, the uneventful (normal) bedded-salt scenario with a waste form that conservatively simulates the release from borosilicate glass, the reference waste form for the DWPF. No credit is taken for chemical interactions with other parts of the engineered system and the rock, or for limited solubility of some waste elements. We refer to this as the REFERENCE waste form. The basecase doses are compared with other doses from representative scenarios, including disruptive events, different waste package release rates, and different geologic media.

In general, we found median dose rates (bestestimates) far below natural background radiation levels for individual doses and nearly trivial results for integrated population doses. The reduction of these small doses by using a lower waste package release rate, the ALTERNATIVE waste form, instead of the REFERENCE waste form is consequently small, even though the reduction factor at times was greater than an order of magnitude. Where the doses were large in the probabilistic analysis (i.e., at high confidence levels), the effect on dose of improving the waste form was small. This indicates that there are other mitigating factors that vitiate the influence of release rates when doses are high. Thus, where one would hope to gain the most from a better waste form, there seems to be little dependence on waste form durability.

\section{Basecase}

The generic layered-salt repository model includes general features of sedimentary basins containing bedded salt. It does not represent any particula: basin. It is intended as a nodel with properties characteristic of a real basin that has had a moderate amount of exploration.

For the basecase individual dose we find that

- For the layered-salt repository with REFERENCE waste form, our best estimate of peak dose rate to an individual using a well located 1.6 $\mathrm{km}$ downstream from a repository (i.e., the $\mathrm{AEl}$ dose) is about 3 orders of magnitude below the dose he would receive from background radiation. If the confidence level of the calculation is increased from $50 \%$ to $90 \%$, then the AEI peak dose increases to $10 \mathrm{mrem} / \mathrm{y}$, still an order of magnitude below background. If, however, the individual is part of the Columbia River water-use system with an average diet of only contaminated food. he will receive approximately $1 / 10,000,000$ of background radiation.

- Improving the waste form by changing to ALTERNATIVE reduces the peak dose obtained from a well one mile downstream over a factor of 10 for doses below the $70 \%$ confidence level. Above the $90 \%$ confidence level, however, there is little or no improvemerit.

For the basecase population dose:

- Integrated population dose over the first million years results in only a 200 person-rem total dose, less than $1 / 10$ of the dose considered to lead to a single additional premature cancer for the $50 \%$ confidence level estimate. Increasing the confidence level from $50 \%$ to $90 \%$ increases the integrated population dose to 2000 person-rem.

- Improving the waste form by changing to ALTERNATIVE reduces the best-estimate integrated population dose calculated using REFERENCE by 190 person-rem in one million years. 


\section{Design Alternative}

In cases where the waste form is assumed to dissolve fairly rapidly, repository design features could have a strong effect on near-field doses. ${ }^{3}$ To analyze the possible effects of repository design on predicted doses, we have calculated the doses from a salt repository with an engineered hydraulic bypass that would provide a path beneath the repository, which is more permeable to the flow of groundwater than the backfilled repository itself.

We found that:

- Bypass increases the containment time of the initial pulse from 7000 to about one million years when all parameters have median values. Also, by using a full uncertainty study at the $90 \%$ confidence level, the bypass reduces the AEI dose by a factor of 50 .

- Using the improved waste form, ALTERNATIVE, does not improve performance of repository with the bypass at the $50 \%$ confidence level. At the $90 \%$ confidence level it improves performance by $0.2 \mathrm{mrem} / \mathrm{y}$ for $\mathrm{AEl}$ and 18 person -rem for integrated population dose.

\section{Alternative Site}

Another leading candidate medium for a defense waste repository is basalt. The basalt model includes general features of flood basalt basins. It is not a simulation of any particular site, but has characteristics similar to those of a real site with moderate exploration:

- The basalt repository yields higher doses (by approximately a factor of 5-50) than the layered-salt repository for the integrated population dose and the peak individual dose one mile downstream. It was a better performer by about a factor of 10,000 th in the layered-salt repository for the individual with his well above the repository. This is because more waste could migrate through the rock barriers in basalt, thus avoiding the well just downstream of the shafts. Including the bypass in the design reduced the dose for the well above the repository to zero.

- Improving the waste form by changing to ALTERNATIVE reduces the basalt repository dose $1.6 \mathrm{~km}$ from the repository by $1 \mathrm{mrem} / \mathrm{y}$ and the integrated population dose by 500-person rem.

\section{Waste Form Release Rate}

Our waste form release rates and their uncertainties (as represented by the median and geometrir standard deviation of a lognormal distribution) are important parameters for the purpose of this paper. We studied the effects of release rates and their uncertainties to see how improvements in waste form technology affect repository safety:

- The low-dose ends of the dose vs release rate curves are sensitive to both release rate and release rate uncertainty, but the high release rate ends of these curves (for $\geq 90 \%$ confidence levels) are insensitive to release rate and release rate uncertainty. This is true for release rates greater than approximately $5 \times 10^{-7} / \mathrm{y}$.

- The choice of waste form should be insensitive to uncertainty of waste form release rate. Where the doses are sensitive to uncertainty, the doses are orders of magnitude below background. Where the doses are significant fractions of background, they are insensitive to uncertainty.

\section{Disruptive Events}

To determine the magnitude of the hazard if future disruptive events occur, we have looked at events that are both sufficiently probable and likely to lead to high doses. The risk from all the important scenarios can be incorporated into a single curve that provides a probabilistic measure of performance:

- Incorporating possible flaws or disruptive events into the analysis changed the best estimates of the peak individual dose rate by about a factor of 3 . This is a small change compared with the dose increase of a factor of 100 between the $50 \%$ and $90 \%$ confidence levels. This result implies that the major risk sensitivities in a permeable, layered-salt system are due to the inability to measure and predict the geohydrologic processes of a given scenario, and not to the effects of disruptive events.

\section{Alternative Criteria}

No definitive standard criteria exist with which forecasts of the radiological consequences of high-level waste disposal can be unequivocally compared. There are several locations in our model where forecasting the individual dose seems reasonable. We chose three different locations. The first dose is from a well just downstream from the shafts, the second is a well one mile from the repository edge, and the third is an average individual who lives in the Columbia River water-use system. The calculated level of dose is several orders of magnitude between an individual who drinks water from a well located one mile dowristream and an individual who obtains his water and food from the Columbic River water-use system. For comparison, the difference in dose oetween different waste forms is typically 
below a factor of 10 . Our results inciicate that great cair should be taken in choosing the location at which the repository risks are to be measured, calculated, or regulated.

\section{Additional Comments}

The results presented in this summary have been taken out of the context of the main body of this work. To provide proper perspective, two important points must be made.

The first point is that we have made many conservative assumptions in the analysis that bias our dose frequency distributions toward high doses. Two examples of important conservative assumptions follow.

The first example is our use of a convective flow model in layered salt. It is possible in a wellchosen site that convective flow in salt is zero. Thus, under nonflawed conditions, the transport of radionuclides to the human environment would have to be either a disruptive event or by Brownian diffusion. If a disruptive event occurs, then the doses obtained are similar to those obtained in convective flow calculations. However, in a probabilistic analysis, the probability of the disruptive event must be folded into the calculation This leads to a smaller risk than predicted by the convective flow probabilistic risk calculation. If no disruptive event occurs, the Brownian diffusion calculations show very low peak dose rates. Thus, the convective flow method will either be valid or lead to conservative results with appropriately low permeabilities. ${ }^{4}$

The second example of an important modeling conservatism is that the release rate was calculated from a leach rate obtained in laboratory ex- periments over short durations with high oxygen content in the water. Because the oxygen content in groundwater is usually low (which would lead to much lower release rates) and because release rates for many radionuclides would likely be constrained by solubility limits, the release rates used in this analysis are believed to be upper bounds.

Many other important conservative assumptions have been made which are appropriately addressed in the main body of the text. Although it is impossible to quantify their effects on the final results, taken together they significantly raise our confidence that the systems studied are safe.

The second point is that the conclusions on the comparison of waste forms in this report do not necessarily scale to commercial waste repository size. The larger amounts of radioactivity in a full-scale, licensed HLW repository could lead to the accessible environment individual receiving peak doses that may be larger fractions of background radiation levels. Lower waste package release rates might have a greater effect under such circumstances in reducing the peak dose rates for the commercial repository. Alternatively, the higher doses could be lowered as greater understanding of repository site, engineered barrier performance, and leaching phenomena allow some relaxation of the conservative assumptions used in this study.

Calculations for a larger HLW repository are recommended to assess what the effects of a high waste inventory distributed over a much larger repository area would be on the AEI dose. The effects on the population dose and the dose to the average individual in the CRP system are expected to be unimportant because they are several urders of magnitude below background levels.

\section{Background and Objectives}

Significant quantities of defense high-level waste have been generated in defense programs at SRP and stored in subsurface tanks. Solidifying the waste for permanent disposal in a deep geologic repository is planned. In the meantime, DOE sponsors research and deveiopment on alternative solid materials to host the HLW, including borosilicate glass. Typical geologic media for the final repository are bedded saIt, basalt, or other media, such as tuff or granite. The choice of a suitable combination of solid form and geologic medium depends in large part on the resulting risk of exposure to future gencrations.

To immobilize SRP wastes in a solid form suitable for permanent disposal, Savannah River is developing a defense waste processing facility. A final EIS has been published for the DWPF. However, the final choice of the DWPF waste form vas left open. To support the choice of a waste form for the DWPF, a technical data base of risks and costs of viakle alternatives is needed. This document provides a risk assessment for the 
leading DWPF waste form, borosilicate glass, and for a waste form defined to have a lower release rate of radionuclides in layered salt and basalt.

Recently the regulatory and adjudication guidance on what constitutes an acceptable risk assessment procedure has tended toward the probabilistic approach. ${ }^{5}$ LLNL has developed substantial expertise in applying probabilistic risk analysis to nuclear waste disposal. We have compiled extensive probabilistic data bases for different media during the past five years. These data bases provide the basis to predict realistically the biological impact of high-level nuclear waste disposal in various geological media, including bedded salt and basalt. A number of studies using this expertise and data base (including sensitivity and uncertainty analyses on risks associated with high-level commercial wastes and spent fuel) have been made for both the Department of Energy (DOE) and the Nuclear Regulatory Commission (NRC).
To satisfy NEPA requirements as currently perceived, we have chosen to provide state-ofthe-art information as consistent as possible with existing national standards. The main standards guiding us in the development of our numerical results were the NRC's 10CFR20, 10CFR50, and diast 10CFR60 and the EPA's draft 40CFR191. To be consistent with current standards we had to develop a model that predicts, not only individual dose at the "accessible environment," but also population dose associated with an extensive water-use system.

This report provides the decision maker with data un long-term risks without a surfeit of technical details. We have limited our discussion to a description of our methods, key assumptions, and findings. A companion document (UCRL-5318882) with broader scope and greater detail is in progress. The third section of this report presents our methods, the fourth section our findings, and the fifth section our technical conclusions.

\section{Technical Approach}

The most probable process for release of significant quantities of radionuclides to the biosphere from a closed, deep, geologic nuclear repositcry is groundwater transport. ${ }^{\text {' The process }}$ involves a scenario that allows groundwater to come into contact with the waste, release the radionuclides, and transport them to the biosphere.

Predicting realistic doses to individuals $w_{\star} \mathrm{O}$ live near a nuclear waste repository requires careful modeling of the repository excavation, its backfill, and its effects on surrounding hydrologic conditions. With current repository designs, any transport of waste to people must start with radionuclide release from one of many spatially separated canisters. In an excavation network the transport of waste from each canister to an individual can occur by many pathways. An observer, were he able to follow the migration of the many waste pulses, would see a system of pulses moving through various pathways at different times and finally arriving at biosphere release points.

Prediction of the transport of radionuclides from a nuclear waste repository also requires careful description of the geology, hydrology, and chemical interactions over long periods of time. To provide a scientific analysis, we must deal not only with the complexity of the phenomena, but also with the uncertainties inherent in the process and in extrapolation of ciata over extended periods (maybe as long as $10^{h}$ y or more). Although it may introduce additional uncertainties, computer modeling is the only appropriate means to quantitatively forecast the behavior of such complex systems. At the outset of this program we reviewed the availabile computer models. They range in degree of complexity from simple, one-dimensional, single flow-path models to those involving highly detailed, three-dimensional, finite-difference and finite-element representation. No one model is capable of incorporating all the details currently being studied. Realism requires judicious choice not only of the processes, but also of the level of detail of their description to be incorporated in the model. Selection of the processes strongly depends on the results required. The results re$n$ ired, in turn, are matters of national policy. In this work we have tried to bridge the scientific and policy needs by incorporating the processes necessary to obtain required, but conservative forecasts.

\section{General Physical Scenario}

Figure 1 is a side view of the general scenario we are studying. It does not depict a specific site, 


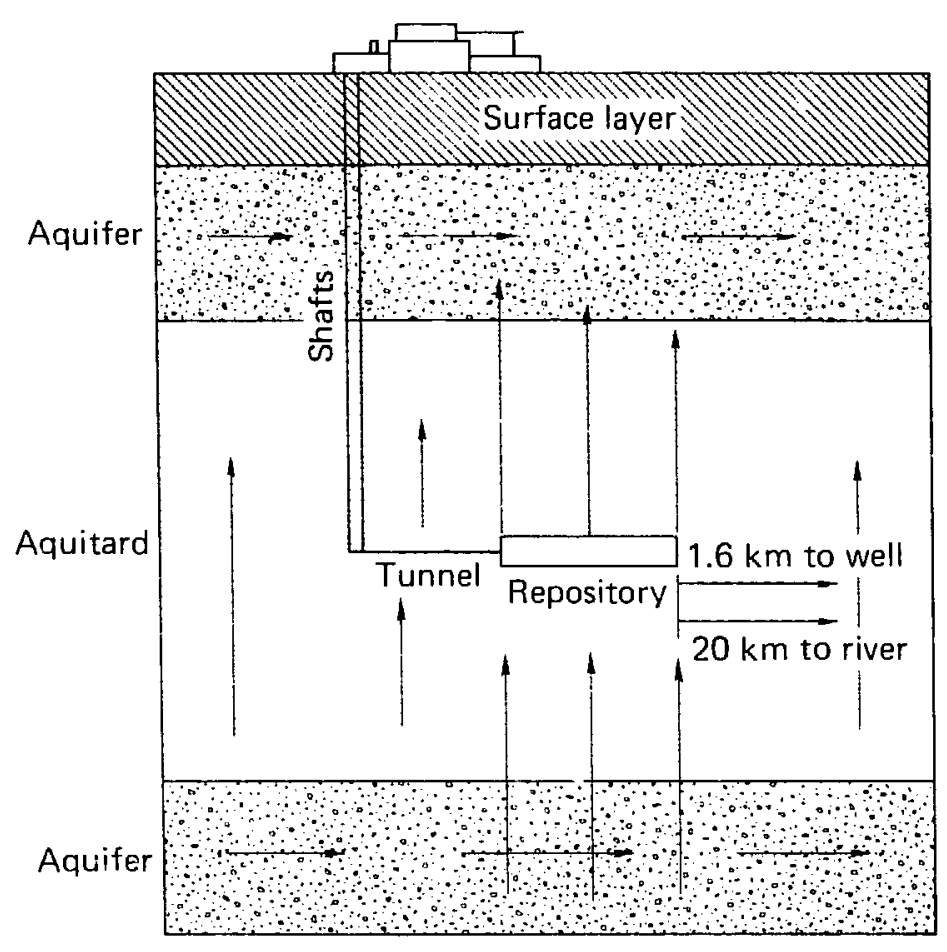

Figure 1. Near-field repository and flow configuration of a generic layered basin.

but represents a reasonable model with characteristic features of real basins. Before the underground facility is built, the regional pressure gradient has a hydraulic gradient from left to rigitt and from bottom to top. The arrows approximate the directions of flow and water flows into the lower aquifer from the left. Some of this water migrates upward into the lower aquitard and traverses it, * finally merging with water in the upper aquifer.

\footnotetext{
- There are four concerns that cause us to use the more conservative convective flow calculation in layered salt: First, layered salt has layered interbeds of clay and shale. Second, laboratory measurements of layered salt permeability tend to have a measurable permeability at the beginning of the experiments. These permeabilities tend to become smaller as the experiments progress, until some lower bound of experimentally determined permeability is reached. We feel that this lowerbound is a conservative value appropriate for risk analysis. If the permeability of salt is experimentally pushed to substan tially lower values, the diffusion-dominated model will beco me more appropriate. Third, every major site repository program has been surprised by unexpected water flows. Asse, WIPP and Salt Vault have all suffered from unexpected water problems. There appears to be a low probability of obtaining a truly "dry" salt repository site. Finally, undetected flaws or future disrurtive events, which could leart to leaching and dispersal of radinactivity to the human environment appear to be conservatively approximated by a probabilistic calculation using a convective-flow model.
}

Excavation causes local perturbations to the regional flow-field, and the hydraulic pressure field around the excavation evolves from one associated with the undisturbed system to a new one consistent with the excavation features. Depending on the permeability and area of the tunnel, for example, more or less of the water will move along the tunnel and up the shaft. Thus, although the boundary conditions for the system remain essentially the same, local flow conditions in the repository can vary greatly because of mine design. Maximum deviations from the virginal flow conditions will occur when the repository storage area, tunnel, and shaft are highly permeable compared to the aquitard. This could be the case if the repository backfill is deteriorated or if large fracture zones are caused by excavation of drifts.

Our accessible environment individual has placed his well $1.6 \mathrm{~km}$ downstream from the edge of the repository. A hydrologic connection to the upper aquifer is established by the fracture zone around the shaft or by a shaft seal that has failed completely by $1000 \mathrm{y}$. Thus, water reaching the top of the shaft becomes a dispersing plume in the upper aquifer. This plume intersects the individual's low-volume well. If the individual drinks water frem his well, he could potentially receive a 
damaging dose from a combination of many toxic radionuclides.*

\section{The MISER Model}

We have developed in the MISER ${ }^{2}$ code a model that is versatile and physically consistent while providing needed results. It has been written to provide a computationally efficient means to study the effects of repository design features in a probabilistic framework in both the near field and far field. MISER is written in a modular fashion to allow rapid implementation of new or improved models. It is user-oriented and implements extensive graphical output. MISER solves a set of equations describing a network of $1-D$ streamtube pathways resulting in a consistent $3-D$ steady-state hydrology, traces "tree branches" of nuclide transport from numerous sources using a propagator approach, and computes dosage to man at risk-sensitive observation points. Monte Carlo techniques are applied, where appropriate, to account for parameter uncertainties and correlations. (See the subsection "Basecase Repository-Uneventful Layered Salt" for an illustrated discussion of results from a Monte Carlo calculation.)

Figure 2 illustrates the qualitative features of a MISER hydrology model. The repository model has both a main (operation) shaft and an air ventilation shaft upstream of the storage area. The storage area is : ndeled with 25 flow cells. The model is symmetric around the centerline location of the shafts and the main tunnel. The horizontal boundary conditions for the basecase scenario are head gradients that cause a regional flow from left to right, parallel to the tunnel.

To display the typical flow cell (shown by the cutaway in Fig. 2 and located near its geometric center), we have depicted the upper aquitard as being transparent. ${ }^{\dagger}$ The typical flow cell is shown

\footnotetext{
"People drink water with as much as 3000 ppm of dissolved salt. (The standard for drinking water is $1000 \mathrm{ppm}$.) Our well scenarios contain substantially less than $100 \mathrm{ppm}$ dissolved salt since the upper aquifer is assumed to be fresh water. The salt contamination comes from salt-saturated water flowing up the shafts.

'Figure 2 show's a 25 -cell numerical model of the storage area. Where it $c, n$ be shown numerically that the number of cells can be reduced, we actually run with fewer cells to lower computer costs. in our analysis in this report we have used a nine-cell model of the storage area. There are six (three when symmetry is employed) cells representing the waste storage rooms and three cells for the tunnels. Each cell has the equivalent of $\left(1.08 \times 10^{3}\right.$ canisters $)$ worth of waste. We have numerically found that this number of canisters per cell can ine repre. sented by five numerical canistrers spacially distributed throughout a waste-storage-room cell.
}

to run from the top of the lower aquifer through the repository storage area to the bottom of the upper aquifer. The hatched strata are the upper and lower aquifers, and shaded areas 1, 2, and 3 are, respectively, the bottom of the lower aquitard, the top of the storage area, and the top of the upper aquitard.

For the typ.cal cell, uncontaminated water flows from the left side of Fig. 2 through the lower aquifer to the cell. It is pushed by the vertical head gradient through Area 1 and up into the lower aquitard. Then it moves through the lower aquitard into the repository storage area whereif the canister has been breached-the leaching waste mixes with the passing water. The contaminated water is then split into three flow paths that move along orthogonal flow directions. The amount of water diverted into each flow path depends on the calculated pressure gradients in the repository. Part of the contaminated water moves parallel to the tunnel into the adjacent downstream flow cell. Another part noves toward the tunnel. Most of the water, however, moves into the upper aquitard barrier where, because of the barrier's permeability, the flow is very slow:

\section{MISER Submodels}

The MISER model can be conceived as a cumbination of four numerical submodels which have been coupled together.

Waste Package. The first submodel is the waste package. It describes the radionuclides originally in the canister and their release as a function of time to the surrounding excavation. The original amount of radionuclides in a canister, a nonstochastic (certain) quantity in this analysis, is then used to calculate the nonstochastic set of radionuclides as a function of time in the system. Thus, the amount of radioactivity in the total system is certain. The radionuclide locations as a function of time are uncertain, however.

The radioactive content of the defense waste contains 87 radionuclides ${ }^{6}$ of which 53 are biologically significant and represent $>99 \%$ of the activity. ORIGEN ${ }^{\top}$ (the ORNL Isotope Generation and Depletion Code) can be used to calculate decay of spent fuel or reprocessed defense waste v's time. From ORIGEN output we obtain a table of artivity $(\mathrm{Ci})$ for each nuclide in the original inventory or produced by decay as a function of time. Figure 3 shows the radionuclide total activity vs time of one canister of defense HLW from Savannah River." The dotted lines trace the groups, i.e., Group $1\left({ }^{99} \mathrm{Tc},{ }^{129} \mathrm{l},{ }^{14} \mathrm{C}\right.$ ), Group 2 (other fission products), and Group 3 (actinides). The solid line is the total activity. 


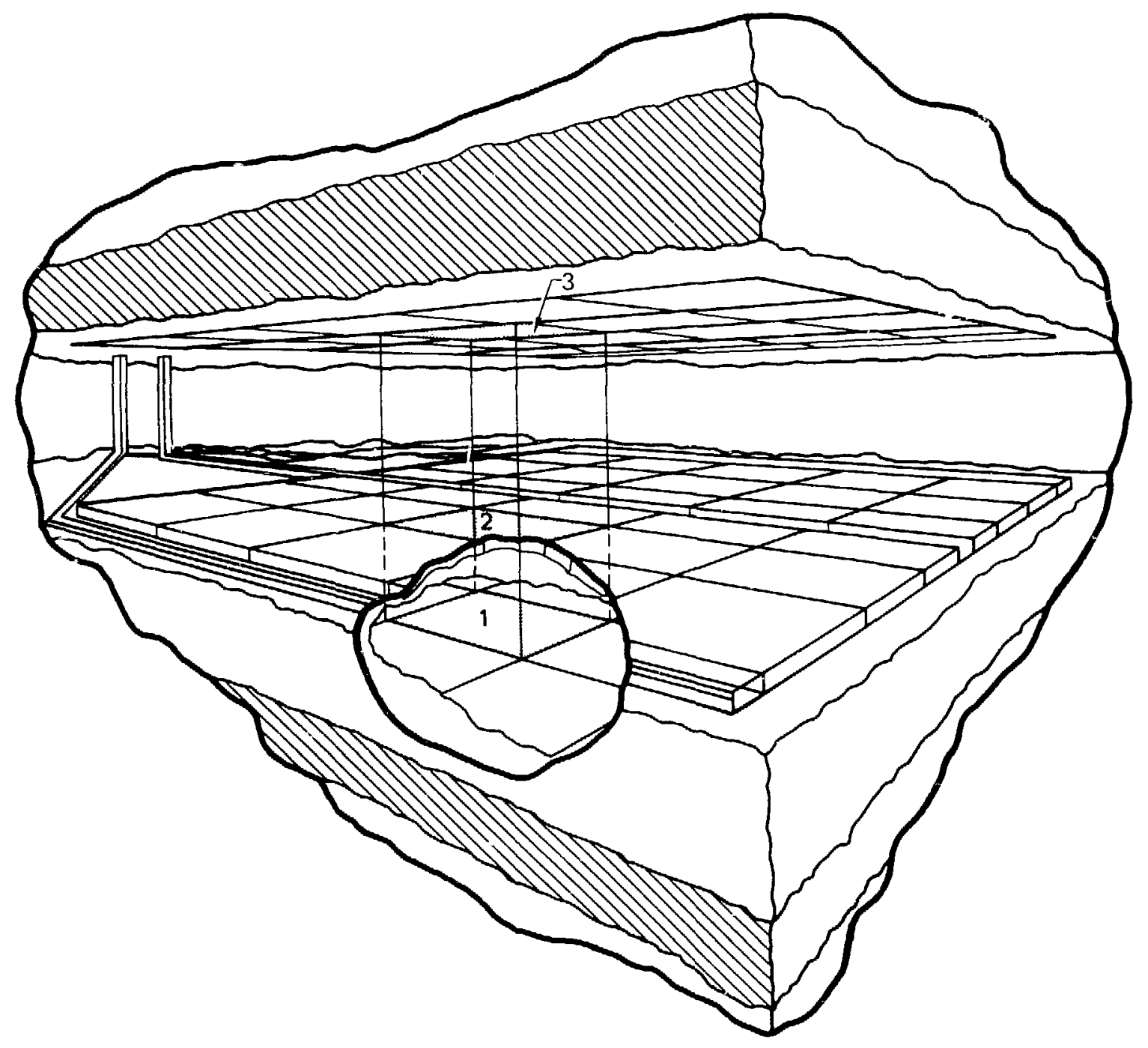

Figure 2. A pictorial representation of a 2-shaft, 25-cell MISER model.

Besides the reasonably well-known quantities of radionuclides vs time, the waste package model in MISER has two parameters with large uncertainties. These are the time of initial release of radioactivity from the package, (referred to here as the breach time) and the duration of the release (or the release time). For the release model, i.e., a model of the amount of radionuclide released as a function of time, any empirical results can be included in MISER by summing over unit pulses using a Green's-function approach. This will incur large computer costs. To avoid this we use a "Gaussian-like" release function. For example, the release functions for release times of $2 \times 10^{5}$ and $2 \times 10^{6} y$ are shown in Fig. 4.
If we assume the waste release mechanism is Gaussian-like, we do not need to convolute the release function with a Green's function. We merely add the terms as though the release pulse were caused by an additional path at the beginning of the transport branch. We truncate our pulse and compute over $M(\geq 20)$ time steps. Finally, these resilts are summed in the result space.

This numerical approach is orders of magnitude more efficient than other models doing similar process analyses. Also, we conservatively assume no solubility lin.its in this analysis by allowing all radionuclides to release at the same rate. 


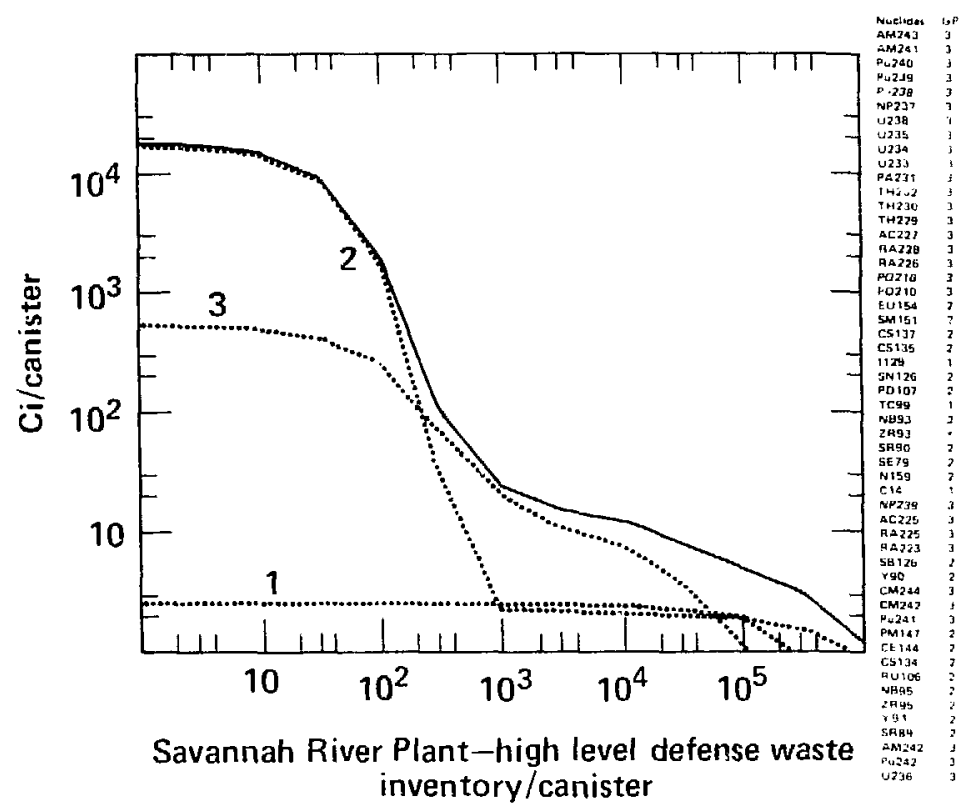

Figure 3. Total activity of one canister of defense HLW by groups.

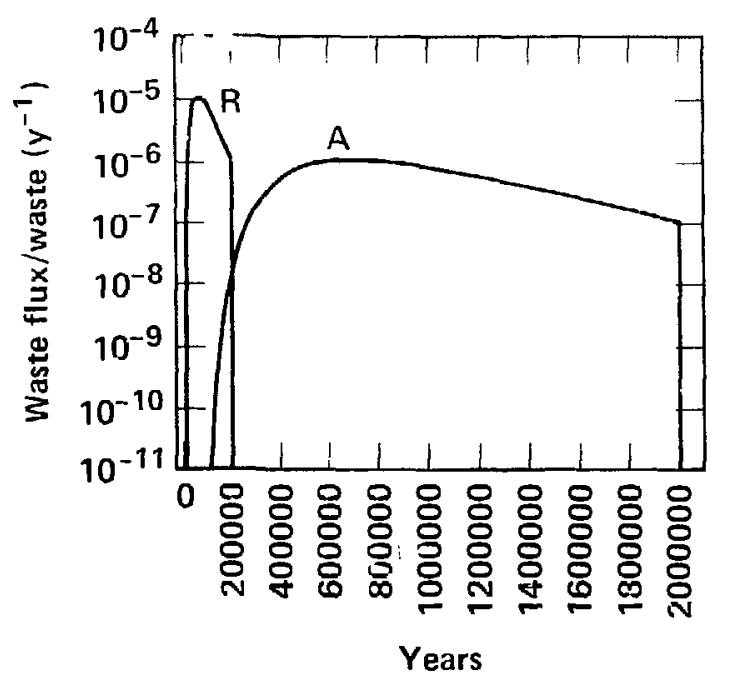

Figure 4. Median dissolution raies of canisters of REFERENCE (R) and ALTERNATIVE (A) waste forms. Both canisters start leaching at time zero.
Our understanding of the release rate is limited at this time. The present values cobtained from characterizing these parameters in labora tory experiments) are limited by not knowing their $m$ situ variability. To date the variability of release rate for real waste at specific sites has not been determined in the measurements of these quantities. The best information arailable is sparse and difficult to generalize, but a general status report is presented here. We use as a baseline release rate. that rate at which a cracked borosilicate glass monolith might be leached based on initial laboratory tests. The actual reluase rate of the glass waste form in a repository may be lower than this value because of solubility limits and sorption properties of engineered barrier materials. Therefore, our haseline rate is a conservative upper bound of the release rate and is, therefore. suitable for use in radiological risk studies. If such an estimated release rate leads to acceptably low doses, a better level of release rate performance would then also lead to acceptably low doses.

These conservative estimates of waste package release rates" (which ignore solubility limits 
and the heneficial effer s of engineered barrier materials) predict tha. he hasecase borosilicate glass form (REFERENCE) will have median dissolution duration of about $2 \times 10^{7} y$ in salt and $10^{7} y$ in hasalt. Our alternative or improved waste form (ALTERNATIVE) is assumed to have a median release duration an order of magnitude better, but with larger uncertainty. The uncertainty on the release duration for the REFERENCE has been approximated by a geometric standard deviation of 10. For the ALTERNATIVE, a geometric standard deviation of 15 was used. For example, this means that about $68 \%$ of the time, values of ALTERNA TIVE release duration will be chosen between $7 \times$ $10^{+}$and $1.5 \times 10^{-} y$ in the basalt case. Better understanding of the stability of wase forms and their environment could lead to substantiai reduction in the number of high dose cases seen for individual doses.

The breach time, an insensitive parameter in the analysis, is taken to be the same for all canisters in the model for a given Monte Cario trial. The median breach time is $1000 \mathrm{y}$. The $98 \%$ interval is from 250 to $4000 \mathrm{y}$. Previous sensitivity analyses indicate that the dose to humans is independent of breachirg time after $1000 \mathrm{y.}^{2}$

Since the release rate parameters are not $\cdots e$.ll understood we have done a sensitivity study on the ralease rate to dr termine the effects of changing our best estimates and reducing the unceriainties of the release rate These results are presented in the subsection Release Rates and Uncertainties."

Excavation and Regiunal Hydrology. The second MISER submodel relates to hydrology. This model includes a network of pathways defined by flow, parameiers that define the flow paths. locations of the source canisters, and location of monitoring points. The hydrology scenario is a hypothetical, representative basin ${ }^{9}$ with an excavation design 1111 shown in Fig. 5. In the storage area, there are assumed to be $6500^{*}$ canisters of defense waste in tunnels containing two rows of canisters spaced $2.3 \mathrm{~m}$ apart. The canister pairs are separated by $2.3 \mathrm{~m}$ along the tunnels. The storage rooms are $5.5 \mathrm{~m} \times 5.5 \mathrm{~m}$ in cross section. Tunnels

\footnotetext{
- Dute to changes in waste immobilization flans at SR , wore or less than 6500 canisters may be emplaced in the repository. However as long as the total amount of waste remains the same, doses are insensitive to the exact number of canisters For example, five canistersicell for thre cells produces essentially the same (alightly cuncervatued result as does 25 comisters/cill.
}

connect the rooms to an access shaft and ventilation shaft. A fracture zone exists around the excavations. This is where the majority of the flow in the excavation occurs unless the backfill has deteriorated. Both the bedded salt basin and the basalt basin are layered. We also allow the model to incorporate an engineered bypass and major flaws, either undetected or caused by future disruptive events.

Under simplifying assumptions, we solve the steady-state hydrology using Darcy's laws and the conservation of water relationship. We assume a network of $N$ paths $(N \geq 2)$ and at least two boundary conditions. The analyst describes the network of stream tubes by assuming all flows are positive from source(s) to $\operatorname{sink}(\mathrm{s})$ at which hydrologic heads are specified. The flow from each path to subsequent paths or boundary conditions is flagged by interactive input in a "connector" matrix. The code then traces all "tree branches" from sources to sinks to produce a set of Darcy law equations:

$\sum Q_{n} Z_{n} / K_{n} A_{n}=H_{k}-H_{1}$ for $m=1,2 \ldots N B$;

$\ln \mid$ fatli $n$ is in branch $m$ !

where

$N B=$ number of tree branches in the network

$Q_{\mathrm{n}}=$ Darcy flux

$\mathrm{K}_{\mathrm{n}}=$ pirmeability

$A_{n}=$ cross-sectional area

$Z_{13}=$ path length

$\mathrm{H}_{\mathrm{I}}=$ boundary head at exit of branch $\mathrm{m}$

$\mathrm{H}_{\mathrm{R}}=$ boundary head at entrance of branch $\mathrm{m}$

$\mathrm{n}=$ path number.

The conservation of water at path junctions also produces a set of equations

$\sum_{i} Q_{i}=\sum_{i} Q_{1}$

where paths $\mathrm{i}$ flow to junction $\mathrm{m}$, paths $\mathrm{j}$ flow from junction $m$, and $m=1,2 \ldots \mathrm{NJ}=$ number of path junctions in the network. In general, $(\mathrm{NB}+\mathrm{NJ}) \geq \mathrm{N}$-the number of paths (or unknowns). In theory, a linearly independent set of $\mathrm{N}$ equations can be chosen. It is, however, numerically more efficient to obtain a rapid least-

\footnotetext{
'Our salt repository model uses 89 flow paths in the network; the becalt refository, 92 paths. In both cases there are four boundary conditions.
} 


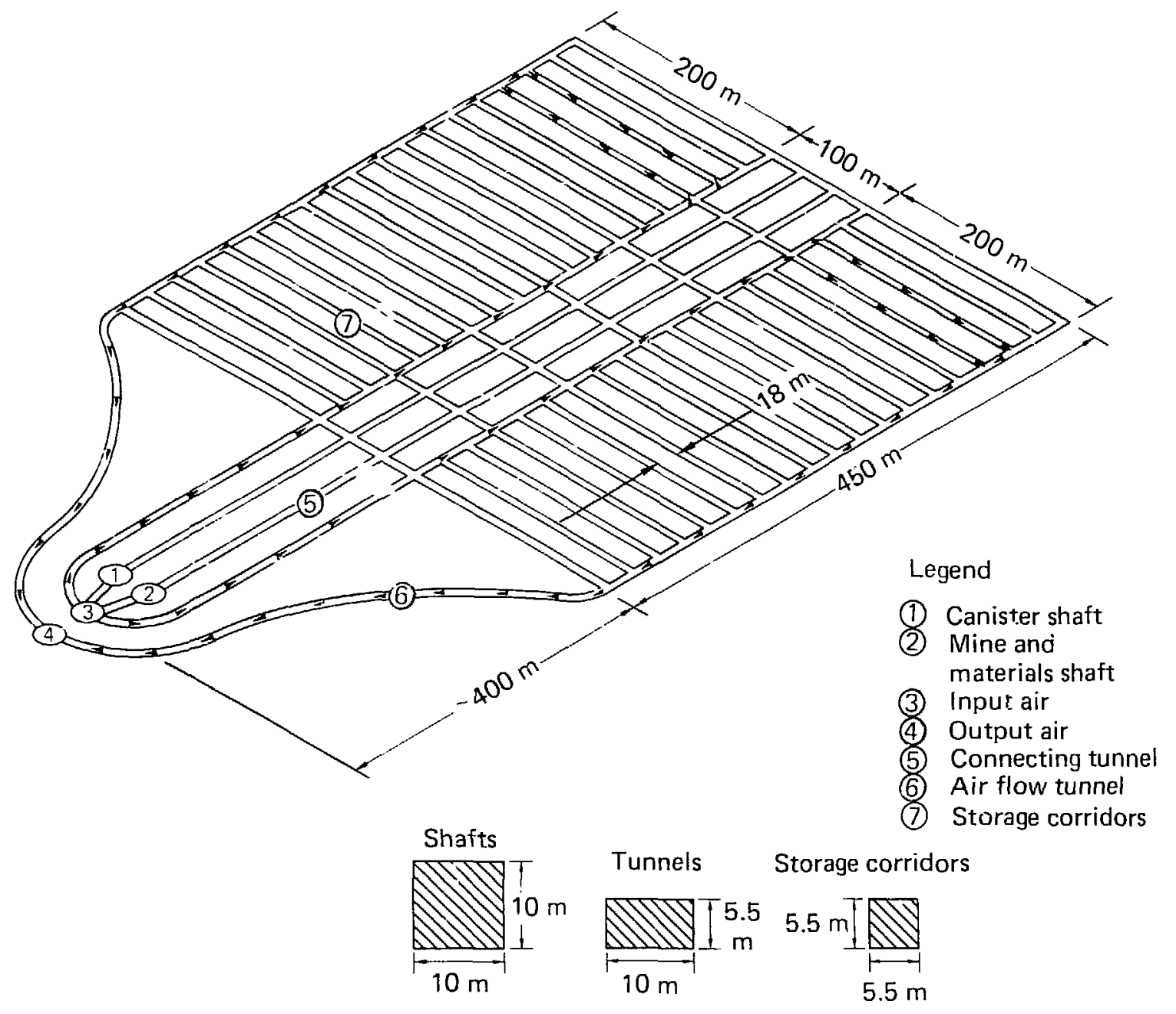

Figure 5. Layout of the mine design. The storage rooms are orthogonal to the main tunnels. Those with ventilation are the ones currently being filled with waste. The area of this design is at least several factors smaller than commercial waste repository designs.

sciuares solution of the $\mathrm{NB}+$, equations for the unknowns, $Q_{1}, Q_{2} \ldots Q_{N}$.

If any $Q_{n}$ is computed to be negative, the code redefines the connector matrix and tree branches so all resultant flows are positive. The conservation laws are used to compute the water partition fractions at each junction to complete the steady-state hydrology solution.

The validity of this stream-tube approximation to a real three-dimensional hydrology should be checked using results from finite-element or finite-difference codes as well as experimental data obtained in well-chosen short-term experiments. Obviously, if the stream-tubes have been chosen far from reality, the approximation will be poor. On the other hand, the size and expense of many computer runs almost precludes the consideration of the three-dimensional codes for sensitivity and uncertainty analyses. Further, the uncertainties associated with the nuclide transport submodel may overwhelm the hydrology model uncertainty.

The fracture zone areas and their permeabilities are among the most uncertain parameters in the hydrological submodel. When disruptive events occur, additional hydrological pathways to the biosphere are created. Since disruptive events are extremely variable in their time and iccation 
of occurrence, our conservative approach is to choose a representative case at a bad location for the flaw and to have the event occur at an early time after closure. The probability of such a scenario occurring is calculated from a rate of occurrence over the policy-dictated time of interest, i.e., 10,100 y. 12.13

Transport Model. When the hydrology results have been calculated, the third submodel, the transport model, is invoked. This develops the radionuclide transport as a function of time and position. The general procedure for transport of radionuclides is to extract from the set of hydrology tree branches that subset which leads from all niiclide sources to all risk-sensitive observation points. We then apply our propagator approach to each series of paths in a branch to approximate the waste flux at the release points. The flux pulses are accumulated on a discretized time line. They are then converted to a hazard or dose. Figure 6A displays the set of pulses arriving at a well $\sim 240 \mathrm{~m}$ downstream of the main shaft. The pulses originate from three waste cells with five "cans" per cell. The transport pulses travel up either the air shaft or the main shaft. Groups 2 and 3 are retarded in the upper aquifer. Figure $6 \mathrm{~B}$ shows the group-by-group summation of the pulses (dotted lines) and the total of all groups (solid line). Our studies have shown that the envelope of waste flux Fig. 6B, is essentially insensitive to the exact shape of inuividual pulses (e.g. Gaussian or Gaussian-like pulses convoluted with step-function releases produce essentially the same envelope).

The radionuclides are divided into three transport groups-the anions, cations (other fission products), and actinides, according to the re tardation factors. We use a different propagator for each group. This procedure makes the submodel extremely fast, which allows for enough trials in a Monte Carlo analysis to obtain confidence levels above $90 \%$ without incurring unacceptably large compliter costs.

We make assumptions in our solution of the convective dispersion equation:

- Flow is slow enough so that instantaneous ion exchange equilibrium occurs, and the ion exchange absorption isotherm is linear, and

- The retardation factor is the same for all radior uclides in the same decay chain.

With these approximations, we write the governing equation in terms of mass flux of the three groups to produce a much simplified transport equation that should provide realistic results when system uncertainties are considered. The as-

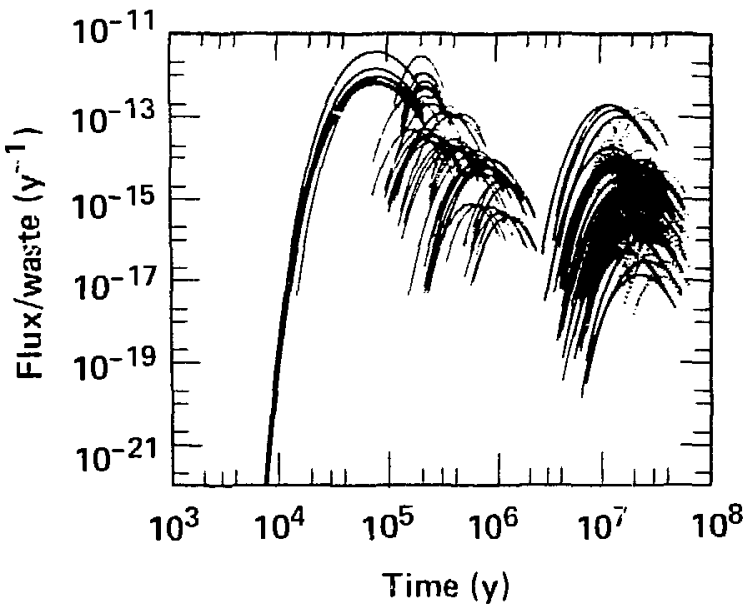

(A)

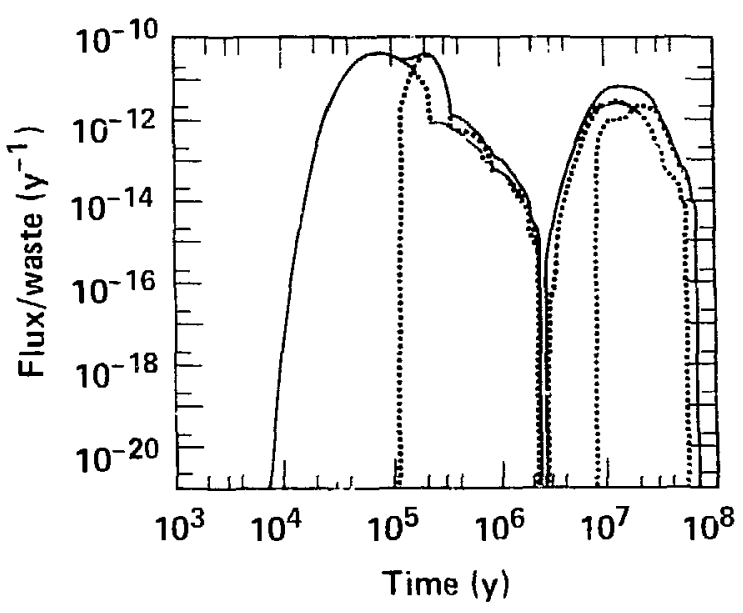

(B)

Figure 6. Pulses and their summation, which arrive at the well above the repository. Figure A shows the Gaussian-like flux pulses, which arrive vs time. Figure $B$ shows the group-by-group and total summation of flux vs time.

sumptions allow us to follow implicitly rather than explicitly, radioactive decay in our transport model. We compute a flux of nuclide groups as a function of time. We then use tabulated results from the waste package and the biological impact submodels as multipliers in the dose calculations.

Biological Impact Models. ie fourth submodel describes the biological impact. To provide a spectrum of results compatible with today's regulations, we use two models: an individual 
drinking from a well at the edge of the "accessible environment," which we call the Accescible Environment Individual (AEI) model and a population dose model for the current Columbia River wateruse system--the Columbia River population (CRP) model. ${ }^{14}$

AEI Dose Model. The intent of this model is to provide a performance measure that has traditionally been used in the regulation of the nuclear fuel cycle, i.e., individual dose. By regulating the maximum dose to individuals of the nuclear work force and the public, acceptable population doses have been maintained.

A man, who drinks 2.2 litres of water per day from a well located at the edge of the "accessible environment" $(1.6 \mathrm{~km}$ downstream from the edge of our repositnry) is used as our model in measuring the safety of the system. Depending on the placement of the well and shaft relative to the repusitory, the man will receive radioactivity from the shaft, through the barrier media, or from both Shaft radioactivity will be diluted during the flow from the shaft to the well. The amount of dilution depends on the distance of travel as well as the relati:0 amounts of water flow in the shaft and the aquifer.

We consider a "sampling well," with diameter much less than that of the shaft. We assume that the withdrawal rate is small enough to ensure that the magnitude and direction of the aquifer's water velocity are unaffected by well operation. Piezometric heads in the aquifer also remain unchanged and we assume the well samples the aquifer water uniformly with respect to depth. Further, to study worst-case AEI dose, we assume the well and shaft are both placed on the centerline of the repository.

The equivalent whole body, 50-y dose commitment discussed in ICRP Publication $30,^{15}$ provides a rational method for combining doses to various organs from diverse radionuclides into a singledose measure. This dose measure can then be used for analysis of repository-engineered features. The basic quantity used for such a combination is the "annual limit of intake" (ALI) for each radionuclide. If an ALI for a nuclide is ingested, then the 50-y dose commitment is 5 rem.

CRP Dose Model. For the CRP model, we have chosen a water-use system fed by a $20-\mathrm{km}$ long aquifer from the repository. For waste located at the Hanford site, the runout would be at least this distance. In CRP, we calculate the population dose assuming no future change in the population and the biologic impact of radiation. This is used for the reference population model for both the layered-salt repository and the alternative basalt repository. Using the Columbia River water-use system, we also calculate the dose that an "average" individual who lives in that population would receive (see subsection, "Alternative Criteria").

Environmental assessment of future releases requires consideration of the cycling of long-lived radionuclides in the biosphere and the possibility of local build-up and concentration. Due to the vast uncertainty about future conditions, the basis of model predictions for times far into the future must be defined carefully. The basic philosophy of CRP is to provide tools for evaluating the consequences of radionuclide release under conditions not too far removed from those experienced today.

CRP transport in surface water systems is calculated using a compartment or box model. Because the release of waste is expected to occur over long time periods, the surface water system is assumed to be in steady state and linear with the input flow of waste. This simplification permits the calculation of the doses per unit input flow of waste, independent of the waste release function.

The CRP transport model computes the con centrations of each radioruclide in soil, sediment, and water systems. The model is composed of compartments for each subsystem and assumes uniform mixing within each compartment. The following dynamic processes affecting concentration are considered: dilution by mixing, diffusion between sediment and water, sedimentation, removal of water and focd products by man, ion exchange, biogeochemical processes, and radioactive decay. The potential for accumulating radionuclides in the topsoil due to irrigation of crop lands is also modeled. The accuracy of this model is limited by how well transfer coefficients between the compartme.its can be specified.

Doses are computed for individuals and populations as a function of living habits and usage. Although estimates of the local demography are not possible far into the future, it is possible to develop reasonable limits to the potential population exposure. The population dose from the aquatic food pathway, for example, depends on the net harvest and not on the size of the local population. Similarly, the vegetable and animal pathways depend primarily on the irrigation rate. Since these pathways are dominant, the potential population dose from a river system is relatively independent of the local demography. Population doses were, therefore, based on estimates of the 


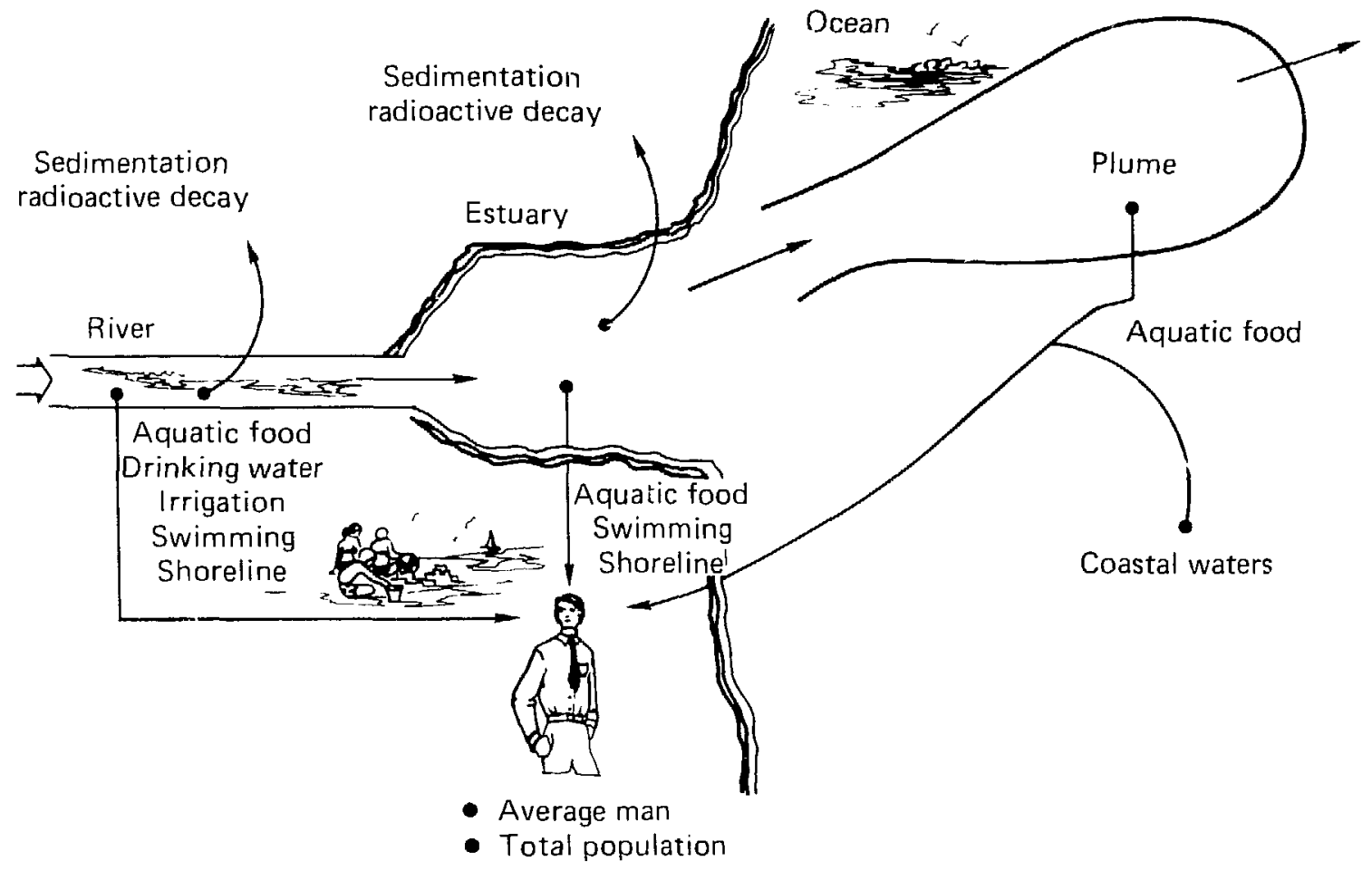

Figure 7. Pathways considered in the CRP model.

usage rates of the water system rather than on population. Dose attri suted to drinking well water from the contaminated aquifer is not considered in the CRP.

The concentrations calculated for the sediment, topsoil and water subsysten:s are used with a simple ecosystem model to give radionuclide dose rates to man. Doses are assumed to be received by ingestion and external exposure. The ingestion pathways modeled are drinking water, aquatic foods, irrigated crops and farm animals. External exposure to both the water subsystems and the topsoil is considered. The pathways considered are summarized in Fig. 7.

A dosimetry subprogram is used to compute hazards on the basis of length of exposure and period of dose commitinent. Doses are computed for the whole body and seven body organs. In addition, an effective "whole-body-equivalent" dose commitment is computed by aggregating doses according to their contribution to cancer risk.
There is no uncertainty in the biological impact models as used in this work and elsewhere. Conceptually, they are used as a monitoring device to obtain relative information. The population model is really extremely uncertain. If these uncertainties were incorporated in the analysis, the dose results recorded would be much more scattered than they are.

A population model is necessary to provide a method of cost/benefit analysis. Since we are mainly concerned with the effects of the physical parameters, and how these uncertainties affect the long-term hazard, fixing the population model does nit seem unreasonable. If population dose ber umes the accepted measure of future risk, using a probabilistic population model would be appropriate, and much larger fluctuations in the iesults would be expected due to population uncertainties. 


\section{Analytical Results}

Our approach to predicting the consequences of defense high-level waste disposal is twofold. First, we construct a method that relies on data and is representative of a repository site with a credible excavation design. This requires calculation of the effects of system uncertainties and excavation detail. Secondly, we focus on a "basecase" (normal), uneventful, bedded-salt scenario with only SRP defense HLW in the repository." The basecase doses are compared with other doses from representative scenarios, including disruptive events and different waste form release rates.

The bedded-salt repository with a simple yet realistic excavation design is studied in the next subsection "Basecase Repository-Uneventful Layered Salt." In "Alternative Waste Forms," the effects of a lower waste form release rate are given as functions of different sites and designs, and the effects of different health standards and future disruptive events are discussed. The way in which understanding waste form behavior affects our results is stuoied in the subsection "Release Rates and Uncertainties" by using ranges of median release rates and uncertainties.

\section{Basecase Repository-Uneventful Layered Salt}

Our generic, layered-salt repository model includes general features of sedimentary basins containing bedded salt. We do not attempt to include specific details of any particular basin. It is intended as a model with the data characteristics of a real basin that has had a moderate amount of exploration.

For our basecase, we follow the generic, layered-salt basin developed by Naymik and Thorson. ${ }^{9}$ This basin contains a locally extensive bedded-salt layer that is discontinuous over the entire basin. Figure 8A shows its cross section, together with the assumed location of the repository. The basin consists of five layers. The central refository layer is bedded salt. It is the least permeable and is sandwiched between two essentially identical shale layers. There are two outer layers of sandstone. These are identical to each other except for thickness. The horizontal distance

\footnotetext{
*An alternative design scenario would be to intersperse defense HLW with commercial waste in a licensed repository.
}

from the repository to the river is $20 \mathrm{~km}$ (see Fig. $8 \mathrm{~B}$ ). The distance to the well at the edge of the accessible environment is $1.6 \mathrm{~km}$. A vertical head drop of approximately $5.75 \mathrm{~m}$ between the aquifers and a horizontal gradient of $0.001 \mathrm{~m} / \mathrm{m}$ are assumeú.

The repository is situated in a local area oi high integrity where the salt bed is quite extensive. On the regional scale, there will be interconnections of the aquifer layers through the barrier rock and salt layers, possibly including joints, faults, and breccia pipes. The rock parameters in the local area around the repository will differ from the regional averages because variabilit; over the region is to be expected. Site exploration will ensure that the repository is placed in a local area with extra competent rock.

Horizontal motion of waste in this study will assume less importance than in Naymik and Thorsen's study because the ratio of vertical to horizontal gradient has been conservatively chosen here as approximately 10 times greater than it is in their work. The lower horizontal gradient leads to conservative near-field doses because: 1) the high ratio of vertical-to-horizontal gradient leads to more trials with waste migrating up the shafts, and 2) the low dilution factor in the upper aquifer leads to greater individual doses in the nearfield.

In some of our scenarios, the local area is assumed to contain isolated pathways, such as faults or fractures. These allow extra water and waste migration. (This is discussed in "Disruptive Events.")

The defense HiW migration is simulated here with convective flow. ${ }^{16}$ Some believe that salt and shale interbeds may not allow convection unless flawed. Migration in layered salt has been calculated for both Brownian diffusion and convective flow. For the uneventful (unflawed) case, the doses from the diffusion simulation were orders of magnitude below those from the convective approach. Considering uncertainties of permeability of layered-salt basins, we have chosen the conservative convection simulation. Also, if there is an undetected flaw that would allow convective !low, the convective flow simulation of the unflawed scenario seems to provide a conservative probabilistic estimate of dose. If this convective flow assumption ulti nately proves to be wrong, the appropriate diffusion calculation could lower results substantially. If our conservative 
(A)

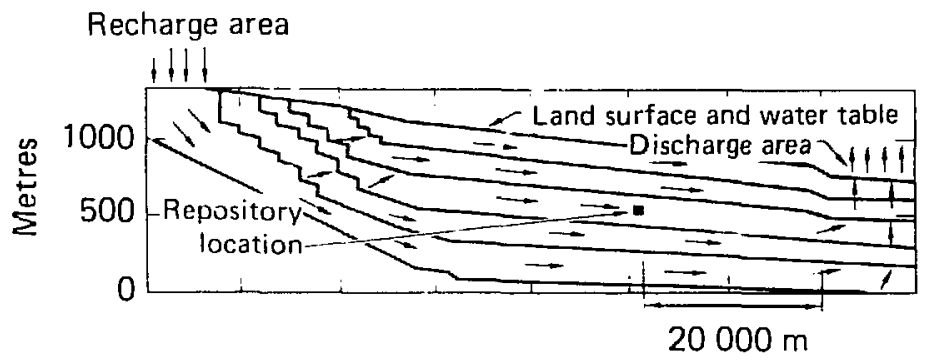

(B)

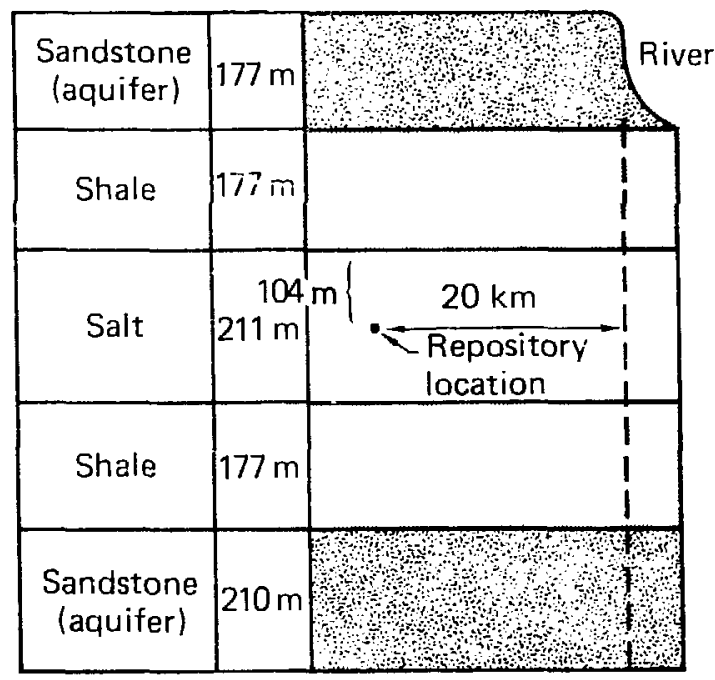

Figure 8. Cross sections of far-field and near-field layeredsalt repository.

forecasts are within acceptable standards, the diffusion approach would only lead to even more acceptable doses. ${ }^{+}$

\section{Monte Carlo Results}

A scenario trial requires a Monte Carlo sample be taken frori cach of the scenario's stochastic parameters. The samples are then used in a deterministic "process" calculation. The deterministic result is binned in the result space." A distribution of the sampied resuits can be plotted as shown in Fig. 9, which displays our basecase results for the peak AEI dose.

"Only the computed nutputs are binned. All uncertain parameters for each $\$$ Monte Carlo trial are chosen from equivalent continunus parent distributions.

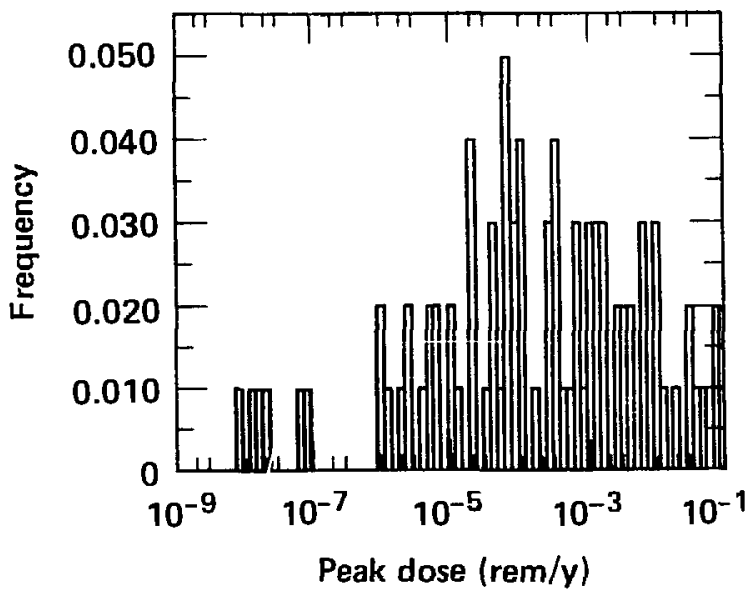

Figure 9. Frequency distribution of AEI peak dose rate for 100-trial Monte Carlo run for layered-salt (basecase) repository with REFERENCE waste form. 
A 100-trial Monte Carlo run was made for the uneventful salt repository with basecaso design and horosilicate glass waste form" A "best estima'e" (BE) of a 0.06 mrern/; AEl dose was obtained and it is the 50th percentile in Fig. 9. The 90 th percentile value in Fig. 9 is $10 \mathrm{mrem} / \mathrm{y}$ and will be referred to as the $90 \%$-confidence level $(40 \mathrm{CL}$ ) dose. This means that we have at least (because of our many conservative assumptions) $90 \%$ confidence that the future repository behavior will cause an AEI dose of less than $10 \mathrm{mrem} / \mathrm{y}$. This dose value is more than 100 times greater than the $B E$. Thus, to be conservative, we could use the $90 \mathrm{Cl}$ as our performance measure; then there would be added assurance that a specified national standard would be met.

Figure 10A show's the same result as Fig. 9, except the curve in lig. 10A has been integrated to produce a cumulative curve. Although Fig. $10 \mathrm{~A}$ doesn't show the detailed structure of Fig. 9, many who are using probabilistic risk information prefer it. In this paper, the cumulative form is used to display our probabilistic results.

Note in Fig. 10A that $15 \%$ of the results were below $10^{-8} \mathrm{rem} / \mathrm{y}$. For these results radionuclides did not flow up the shatt. Thus, radionuclides had to migrate slowly through the upper aquitard to reach the biosphere. This either caused: 1 ) sufficient delay so that no dose was seen in one million years, or 2) dilution in the upper aquifer so great (due to the slow leakage of radionuclides from the upper aquitard into the aquifer) that $16 \%$ of the time, the peak dose in the first million years was below the lowest value on the scale. For population dose, our basecase results are integrated for one million years. Fig. 10B shows our basecase population dose.

Table 1 is the expanded set of results for the uneventful scenario. Here, we have included performance measures of peak individual dose rate (rem/y), integrated population dose (person-rem), and peak individual radioactivity ingested per year $(\mathrm{Ci} / \mathrm{y})$. Arross the top of Table 1 we see the

\footnotetext{
- The dose measures are binned with 10 bins/decade. Wo have compared the results of 5 independent runs of 100 trials each, as well as those of a 500 -trial run. Generally, the statictics fall within \pm 2 bins and the probatility-duse-is-exceeded accumulant plots escentially lin over each other. In the counting process for pircentiles, we choose the first bin in which the count exceeds the percentile. For example, the accumulant of bin $n$ may contain $89^{\circ}$, whereas bin $n+1$ may contain $97 \%$. In this case, the 90th percentile is associated with bin $n+1$ dose values. We make no attempt to interpolate. This implies that, in general, the reported percentiles are on the conservative side.
}

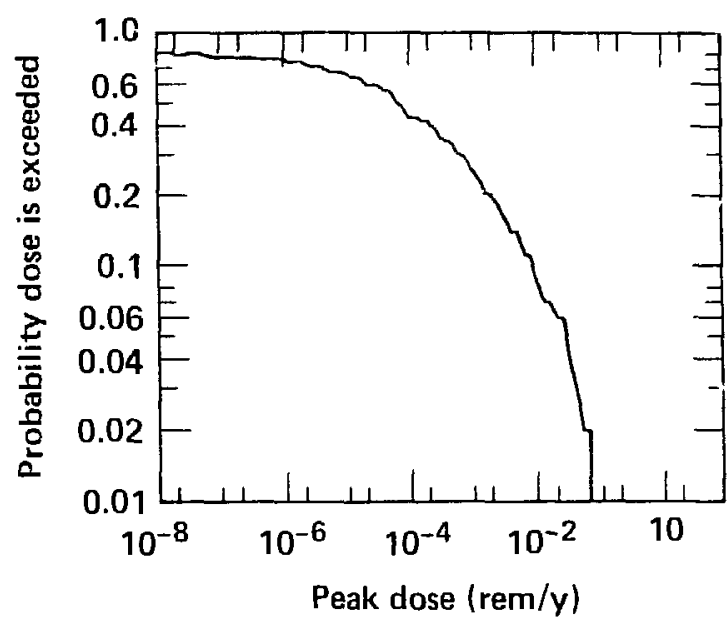

(A)

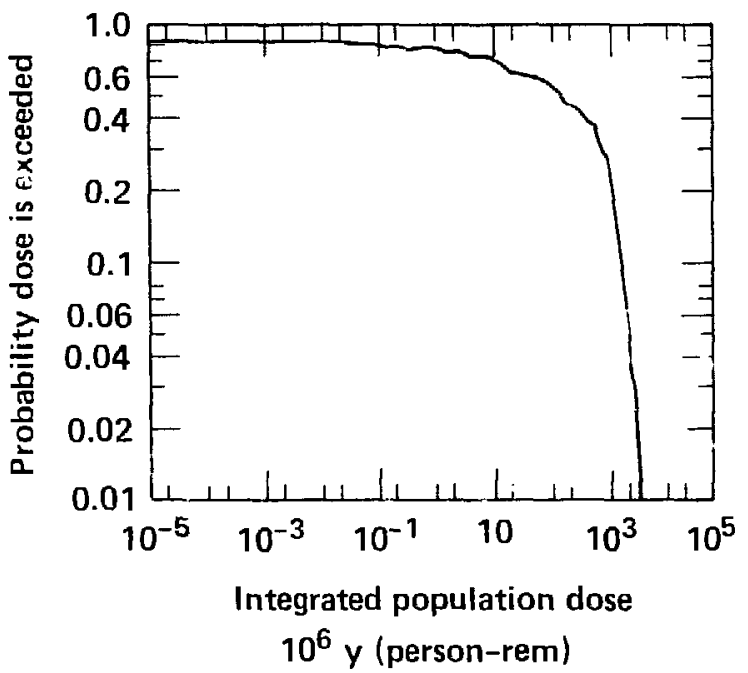

(B)

!igure 10. Cumulative distributions for the layered-salt (basecase) repository. Figure $A$ presents the same AEI results as Figure 9. Figure $B$ represents the probabilistic results for the million-year integrated population dose.

25th, 50th, 75th, 90th percentiles, and the maximum value of the dose obtaned in 100 trials. The 50 th percentile is our best-estimate result, and in most cases is similar to the result we would obtain if we used all median values to describe a scenario. The various perfori tance measures are

- Limiting individual (LI): this individual has located his well about $0.25 \mathrm{~km}$ directly downstream from the shafts. 
Table 1. Expanded basecase tabular results.

\begin{tabular}{|c|c|c|c|c|c|c|}
\hline \multirow[b]{2}{*}{ A. } & & \multicolumn{5}{|c|}{ Peak dose rate percentiles } \\
\hline & & 25 & 50 & 75 & 90 & Max \\
\hline Limiting individual & $\mathrm{rem} / \mathrm{y}$ & $3 \times 10^{7}$ & $2 \times 10^{3}$ & $5 \times 10^{2}$ & $2 \times 10^{1}$ & $3 \times 10$ \\
\hline (above repository) & $\mathrm{Ci} / \mathrm{y}$ & $2 \times 10^{10}$ & $2 \times 10^{7}$ & $3 \times 10^{6}$ & $3 \times 10^{-5}$ & $1 \times 10^{-3}$ \\
\hline Accessible environment individual & $\mathrm{rem} / \mathrm{y}$ & $1 \times 10^{6}$ & $6 \times 10^{-5}$ & $1 \times 10^{-3}$ & $1 \times 10^{-2}$ & $8 \times 10^{-2}$ \\
\hline$(1.6 \mathrm{~km}$ from repository) & $\mathrm{Ci} / \mathrm{y}$ & $1 \times 10^{-9}$ & $8 \times 10^{8}$ & $1 \times 10^{6}$ & $8 \times 10^{6}$ & $1 \times 10^{4}$ \\
\hline Columhia River average individual & $\mathrm{rem} / \mathrm{y}$ & $5 \times 10^{11}$ & $3: 10^{9}$ & $3 \times 10^{8}$ & $2 \times 10^{7}$ & $1 \times 10^{6}$ \\
\hline \multirow[t]{2}{*}{ Population dose } & person-rem/y & $8 \times 10^{6}$ & $6 \times 10^{4}$ & $6 \times 10^{3}$ & $5 \times 10^{-2}$ & $3 \times 10^{-1}$ \\
\hline & & \multicolumn{5}{|c|}{ lntegrated dose percentiles } \\
\hline B. & & 25 & 50 & 75 & 90 & Max \\
\hline CRP for $10^{+} y$ & person-rem & $<2 \times 10^{8}$ & $<2 \times 10^{-8}$ & $1 \times 10^{3}$ & $2 \times 10^{1}$ & $2 \times 10^{2}$ \\
\hline CRP for $10^{5} y$ & Person-rem & $4 \times 10^{-3}$ & $9 \times 10^{0}$ & $1 \times 10^{2}$ & $9 \times 10^{2}$ & $3 \times 10^{3}$ \\
\hline CRP for $10^{6} y$ & Person-rem & $3 \times 10^{0}$ & $? \times 10^{2}$ & $1 \times 10^{3}$ & $2 \times 10^{3}$ & $4 \times 10^{3}$ \\
\hline
\end{tabular}

- Accessible environment individual (AEI): he is located $1.6 \mathrm{~km}$ downstream from the repository.

- Columbia River average individual (CRI): this individual is located $20 \mathrm{~km}$ away from the repository and is part of a community that uses the Cr!umbia River water system. He has an average use pattern, but eats only contaminated foods.

- CRP dose rate: this is the dose per year to the population using the Columbia River water system.

- CRP for $10^{+} y$ (CRP4): this is the time-integrated population dose for the first 10,000 years after closure of the repository.

- CRP for $10^{5}$ y (CRP5): same as above, except time integration is for 100,000 years.

- CRP for $10^{6}$ y (CRP6): same as above, except time integration is for one million years.

Tables similar to this one, showing the expanded set of performance measures, are included in the appendices of a companion document. ${ }^{17}$ For our purposes here, we only use the most relevant output, i.e., peak AEI and CRP for $10^{6}$ y (CRP6) doses as our primary displays. In "Alternative Criteria," we discuss the effects of using other performance measures.

As shown in Table 1, the AEl best-estimate dose is 3 orders of magnitude below backgrutund radia-

\footnotetext{
-We recognize that, strictly speaking, the Columbia River use system is appropriate only for the repository located in basalt. There are no salt regions of interest in the Pacific Northwest. However, for comparison, we will use the same river/population system for both media.
}

tion for a layered-salt repository with simple design and REFERENCE waste form. The 9OCL dose is an order of magnitude below background. The population dose-even at the 90CL-is trivially small (about 2000 person-rem in a million years). These results should be biased on the high side, because release rates, unimited by solubility and Darcian flow in unflawed salt, were conservatively assumed.

\section{Alternative Waste Forms}

In this section we discuss the effects of improving the waste form's release rate by comparing the results from a baseline release rate and a generic "improved" release rate. Improved release rates would likely result from modeling the detailed chemical interactions of the waste elements. Also, improved releasse rates would result from using a more durable waste form, such as ceramiclike SYNROC-D. ${ }^{18}$ There are many possible scenarios for which release comparisons can be made. In this section, we choose a representative set of alternative scenarios, for example, a repository design with bypass. We compare scenario forecasts for the two release rates using these representative scenarios.

We compare system performance for the two release rates, REFERENCE and ALTERNATIVE: 1) in layered salt; 2 ) in basalt; 3 ) with better design; and 4) for alternative criteria. We alsc look at how disruptive events might change our results. For each scenario we tabulate the peak AEI dose and the integrated CRP population dose for $10^{6} \mathrm{y}$. For both ALTERNATIVE and REFERENCE, we 


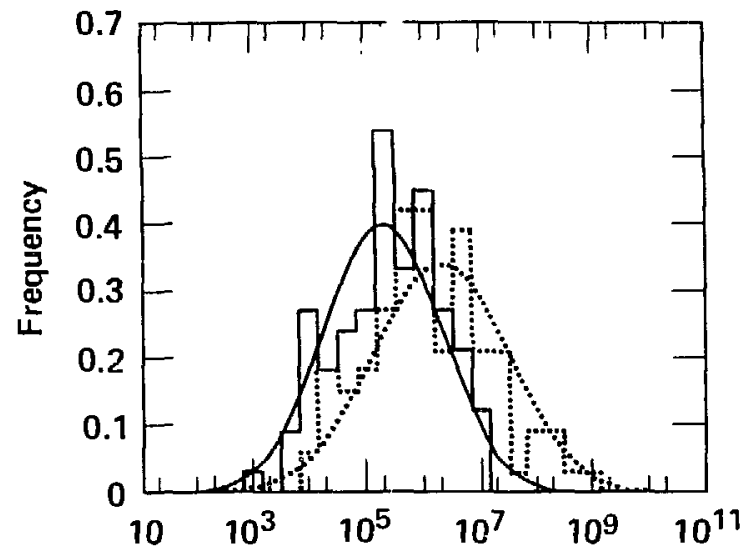

Dissolution time $=1 /$ dissolution rate $(y)$

Figure 11. Histogram comparison of selections of median leach duratious for REFERENCE (solid line) and ALTERNATIVE (dotted line) for a sample Monte Carlo run. The parent populations are also displayed.

present computer overlay comparisons of results with the basecase site and design.

Figure 11 shows representative 100-trial histograms and parent populations for REFERENCE (solid line) and ALTERNATIVE (dotted line) release durations. The REFERENCE geometric mean release duration is $2 \times 10^{5} \mathrm{y}$. For ALTERNATIVE it is $2 \times 10^{\circ} \mathrm{y}$. The geometric standard deviations are 10 and 15 for REFERENCE and ALTERNATIVE, respectively. Alihough it does not occur in Fig. 11, low-probabi'ity, high-release-rate samples for both waste forms could be quite similar.

Numerically, the samples chosen from the distributions are truncated at 3.4 standard deviation. The waste form probability distribution functions are not presently correlated with other parameters, such as the flow rates past the canisters. We chose not to correlate the release rate in this work because their relationships with other parameters are not sufficiently known to justify this added model complexity.

Our knowledge (i.e., uncertainty) of the release rates is very limited. Thus, the geometric mean and standard deviation representing release may also be taken as uncertain. Therefore, we have examined the sensitivity of our results to these choices (see "Release Rates and Uncertainties"). The analysis in the aforementioned subsection is actually a second-order uncertainty analy- sis, e., a study that looks at effects of uncertainty on parameters representing first-o.der uncertainty.

\section{Basecase}

Figures $12 \mathrm{~A}$ and $\mathrm{B}$, respectively show $\mathrm{AEI}$ and CRP6 doses for the layered-salt site. Table 2 summarizes the effects of using ALTERNATIVE rather than REFERENCE. Figure 12A shows that

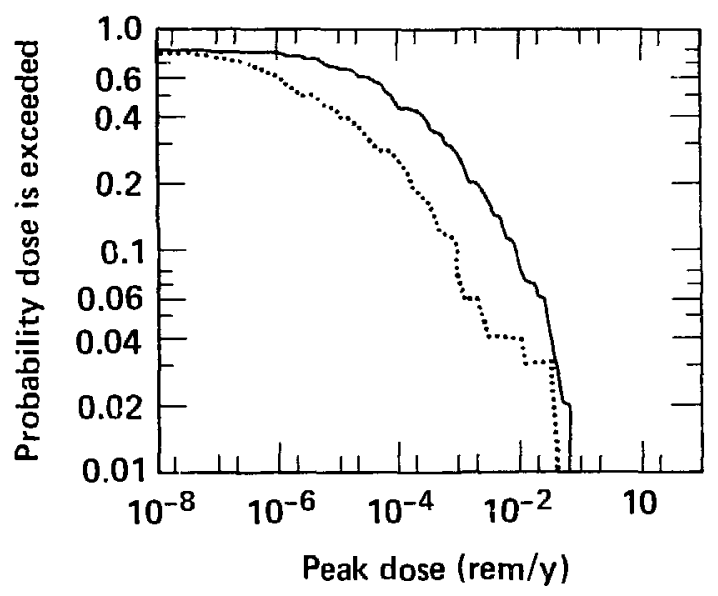

(A)

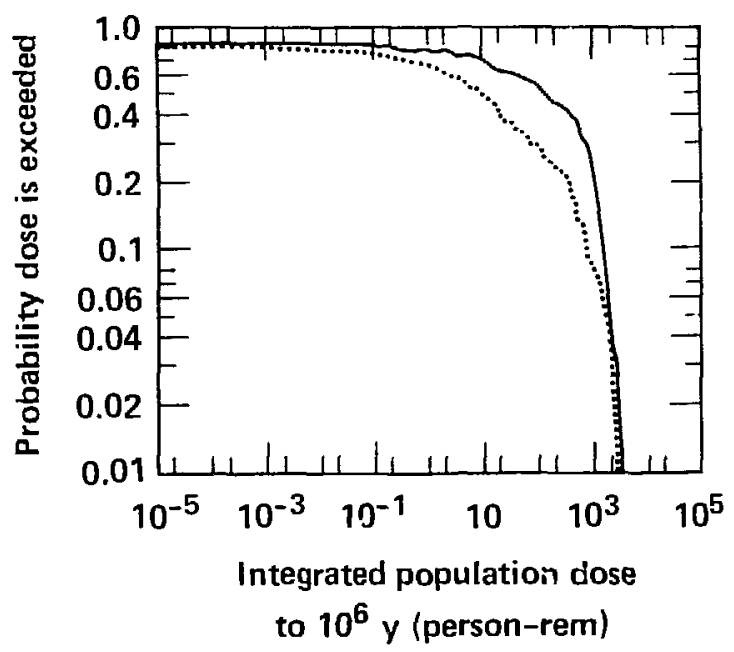

(B)

Figure 12. Comparison of REFERENCE (solid line) and ALTERNATIVE (dotted line) for basecase layered-salt and basecase design. Figure $A$ shows the probabilistic resulis for the AEI dose rate. Figure $B$ is for the million-year integrated population dose. 
Table 2. Comparison of REFERENCE and ALTERNATIVE waste package release for basecase site and desigr.

\begin{tabular}{lcccc} 
& \multicolumn{2}{c}{ AEI (rem/y) } & \multicolumn{2}{c}{ CRP6 (person-rem) } \\
Case & BE & $90 \mathrm{CL}$ & BE & $90 \mathrm{CL}$ \\
\hline REFERENCE & $6 \times 10^{\circ}$ & $1 \times 10^{2}$ & $2 \times 10^{2}$ & $2 \times 10^{3}$ \\
ALTERNATIVE & $2 \times 10^{\circ}$ & $1 \times 10^{3}$ & $1 \times 10^{1}$ & $8 \times 10^{2}$ \\
\hline
\end{tabular}

the improvement of ALTERNATIVE/AEI* dose over REFERENCE/AEI dose is better than a factor of 10 for probabilities below the 95CL. A general tendency, however, for the probabilistic curves to converge at high doses appears throughout our results. This indicates that there are other prc cesses tending to dominate the dose when release rates are sampled at sufficiently high ievels.

Figure 12B show's that ALTERNATIVF/CRP6 and REFERENCE/CRP6 doses are nearly the same at the high side of the curve. Only below the $70 \mathrm{CL}$ does the lower release rate improve the doses by an order of magnitude. Above the $90 \mathrm{CL}$, the predictions are almost identical.

$A$ comparison of $A E I / B E$ doses with accepted risk standards shou's thein to bo orders of magnit ude below the standurds. The REFERENCE/90CL/AEI dose is a factor of 50 below the $500-\mathrm{mrem} / \mathrm{y}$ level (used in 10CFR20 for operating nuclear facilities). ALTERNATIVE/9CCL/AEI dose is a factor of 10 better than REFERENCE/90CL/AEI dose.

The population doses for the worst case shown in Table 2, i.e., REFERENCE/90CL, indicate that in the first million years there might be one premature cancer. ${ }^{i}$ The improvement of ALTERNATIVE over REFERENCE for the 90CL/CRP6 is only a factor of about 2. ALTERNATIVE produces a net reduction of ahout 1200 personrem in a one-million-year period, or only approximately $1 \mathrm{mrem} / \mathrm{y}$ to the population when averaged over one million years.

\footnotetext{
"We will ure a string if aystem characteristics (e.g., RFFERI VCF,CRTh SAl.T/9OCl.) to specify a particular case. The uning relers to the REFERENCE waste form, the $10^{\circ} \mathrm{y}$ populatirn dexte the alt sitt', and the $90 \%$ confidence level. It is murh briefer and, once it becomes familiar, provides a better mental ficture than a string of phrases. There will be no preferred urdering in the string of system characteristics.

'Wi use the BEIR recommendations on biological effects as tha comversion factor from person-rem to premature cancers
}

\section{Alternative Site}

Another leading candidate medium for a defense waste repository is basalt. The basalt site currently being investigated is at the Hanford Reservation. This is located on the Columbia River Plateau, which is a vast upland built of relatively recent basalt flows. Our description and model of the basalt repository closely follows a description developed by Golder Associates, Inc. (1978). ${ }^{14}$

Typical basalt basins are made up of layered, extrusive igneous rock caused by multiple flows of hot, low-viscosity molten rock. Individual basalt flows generally range from a few feet to tens of feet thick, but with some flows exceeding $200 \mathrm{ft}$ in thickness.

The source of the Columbia River Plateau basalt was not from a single central vent or series of them, but from a series of tissures, each of which was several miles long. An individual flow was probably fed by several fissures erupting simultaneously. The flows spread almost like water for great distances.

These flows sought the lowest places, filling the old valleys and encroaching on the flanks of hills and mountains. In time, the original topography was buried and a relatively flat basalt plain was constructed. As the flows spread over a region, they interrupted the drainage, damming streams, and giving rise to local lakes and swamps in which sediments accumulated. Because the Miocene climate was considerably more moist than at present, the processes of weathering, erosion, and deposition could rapidly transform an initially barren flow into one of rich soil and abundant vegetation. The landscape that was developed on the top of one lava flow was buried beneath the next flow, creating interlayers of various thickness between basalt flows. When successive eruptions were close in time, the buried surface was relatively smooth and barren, consisting only of a slightly weathered treeless surface from the preceding flow.

Thus, thick basalt sequences consist of complex interlayering of dense, but strongly jointed 
basalts, clay's, sands, and gravels. The hasalts may be expected to have fracture permeability and the sands and clays interstitial permeability. Some lavers of basalt are significantly less fractured and the repository would presumahly be placed in one of these. Some of the clay layers can also be of low permeability. A complex flow regime can resuit. Figure $13 \mathrm{~A}$ show's a generic basalt basin.

In basalt basins. sources of fresh water are likely to be tapped by wells. Aquifers within sequences examined to date tend to contain fresh water. The basalts studied are located in a desert environment. Thus, the potential release of waste through wells is a critical factor in the suitability of basalts $f_{c i}$ defense HLW repositories.

It is not practical, at this time, to model each of the numerous, rather thin, basalt flow's and interleds found within a thick basalt sequence. Instead, equivalent thicknesses of rock layers are used. These equivalent thicknesses are based on the estimated percentages of five types of layers existing in basalt sequences. They are

- Dense, relatively unfractured basalt.

- Fractured and weathered basalt.

- Coarse-grained interbeds and volcanic rubble.

- Fine-grained interheds.

- Very dense basait.

Our generic basalt model inclucies general features of flood hasalt basins. It is not a simulation of any particular site, but rather it is modeled to have characteristics similar to those of a real site with moderate exploration. The basin modeled includes an extra-competent layer of very dense basal: in which the repository is placed. The design of the repository is the same as the design used in layered salt and is shown in Fig. 5. The basin is simulated by six layers shown in Fig. 13B. Because of their similar permeabilities, the fine interbeds and dense basalt layers have been modeled as a single hydrologic element. Directly above the very dense basalt layer is a permeable layer of sand and gravel. This provides a highly conductive pathway where the waste can move horizontally towards any vertical pathway to the upper aquifer. The very dense basalt, coarse interbeds, fine interbeds, and dense basalt layers are sandwiched between two aquifers consisting mainly of fractured basalt. These two layers are essentially identical to one another.

The vertical artesian head between the two aquifers is taken as $5 \mathrm{~m}$, and the horizontal gradient is chosen as $0.001 \mathrm{~m} / \mathrm{m}$. As in the layered-salt repository scenario, the well is assumed to be lo- cated $16 \mathrm{~km}$ from the edge of the repository. The river is assumed to be located $20 \mathrm{~km}$ arrav

Results. Figures $14 \mathrm{~A}$ and $\mathrm{B}$ show the probabilis tic results comparing doses from the basalt and salt sites for the AEl and CRI'6 doses. The layered-sali curves are labeled " $S$ " and the basa't site predictions are labeled "Ba". First we notice for $A E I$ and CRP6 that the basalt doses are generally higher than the salt doses. Also, the difference in the doses for basalt and salt becomes smaller, the higher the dose. For the CRP6 dose, the difference nearly disappears at about the $70 \mathrm{Cl}$. This is true for either the alternative site or the alternative waste form. This implies that for high doses there is ve: $y$ little sensitivity of CRP6 to alternative sites or, for that matter, alternative waste forms.

The second item of note is that the alternative waste form release rate makes a bigger difference when used in the salt repository than when it is used in a hasalt repository. For example, at $50 \mathrm{Cl}$. the waste form difference in salt is a factor of approximately 30 and a factor of $10 \mathrm{in}$ basalt. At $90 \mathrm{Cl}$, it is 10 for salt and 4 for basalt. This again points out, the higher the predicted dose, the less effect a change of waste form has in reducing it. This result is due to other physical attributes of the excavation and transport which cause low dose rates, even when high release rates have been sampled.

In Table 3, the AEl dose is a muxmum it $1 \mathrm{mrcm} / \mathrm{y}$ for REFERENCE/B.AS.ALT/BE. This ciose increases to a value of $40 \mathrm{mrem} / \mathrm{y}$ for REFERENCE BASALT/90CL. For ALTERNATIVF/BASALT/ $90 \mathrm{CL}$, there is an improvement to $10 \mathrm{mrem} / \mathrm{s}$, a factor of 4 , due to waste form improvement. All AEI doses shown in Table 3 are at least a factor of 10 below natural background radiation.

The largest best-estimate population dose in Table 3 is for BASALT/REFERENCE. It is 1000 person-rem accumulated in one million years. The largest $90 \mathrm{CL}$ dose in the table is 2000 person-rem. This occurs for SALT/REFERENCE, BASALT/ REFERENCE, and BASALT/ALTERNATIVE. SALT/ALTERNATIVE is 800 person-rem.

It is estimated that 2,000 rem to the popt!..1tion creates less than $40 \%$ probability that a single premature cancer will occur. If a salt repository is chosen, our prediction at the $90 \mathrm{CL}$ is that the ALTERNATIVE waste form will improe't the system performance by reducing population dose about $1000 \mathrm{per}$ son-rem in onc million years. This leads to about $20 \%$ reduction in the probability of the repository causing a single premature cancer in a million years. 
(A)

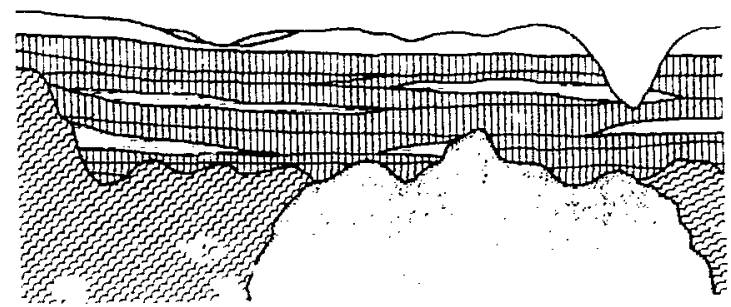

Legend

$\square$ Crystalline
Metamorphic
IIIIII Basalt flows

(B)

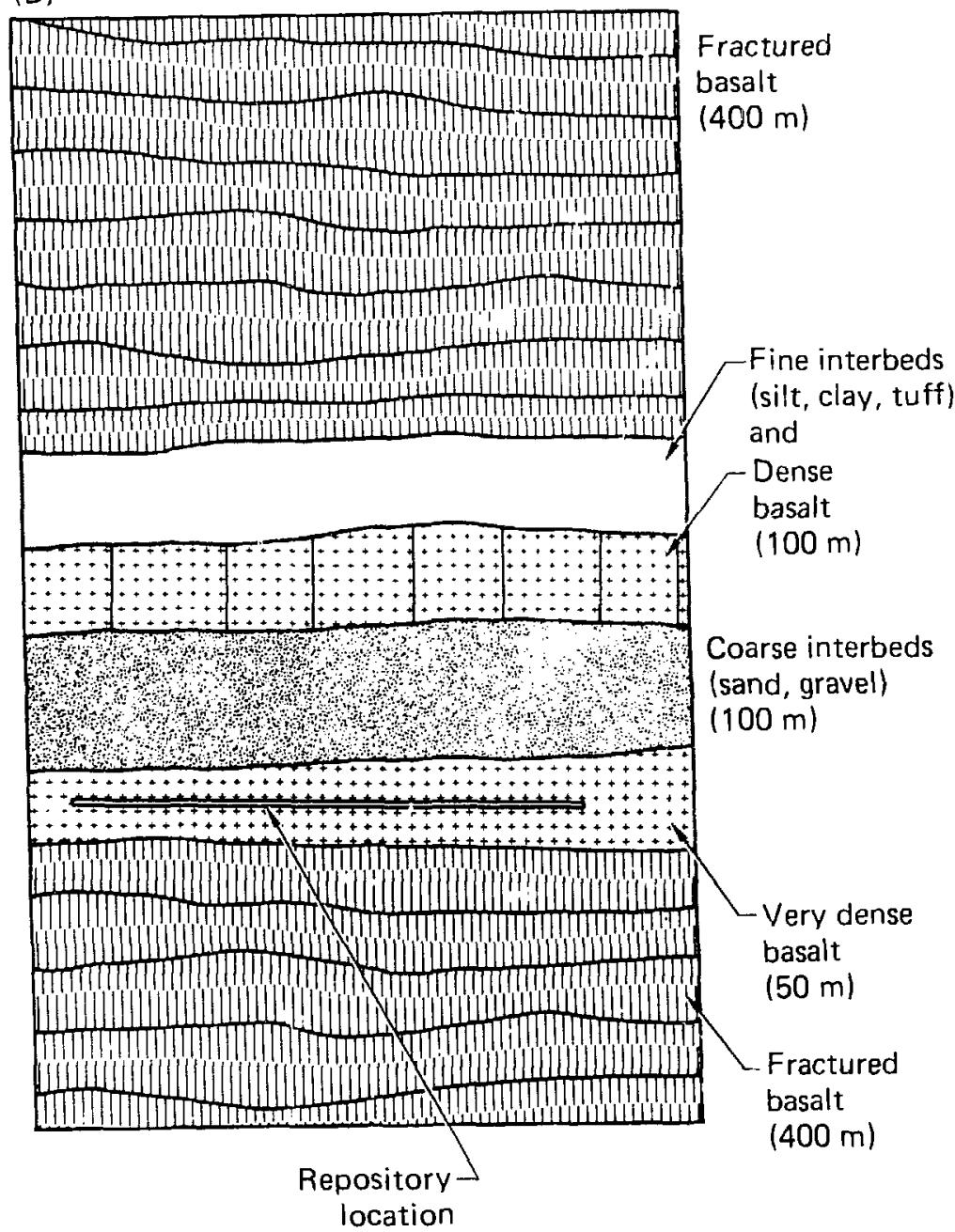

Figure 13. Near-fieici and far-field cross sections of a layered-basalt basin. Figure B shows the near-field configuration we used in this study. 


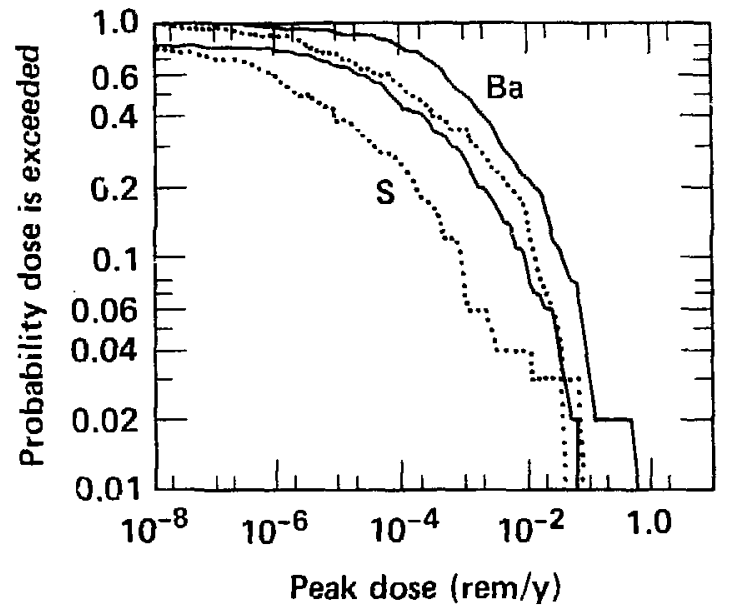

(A)

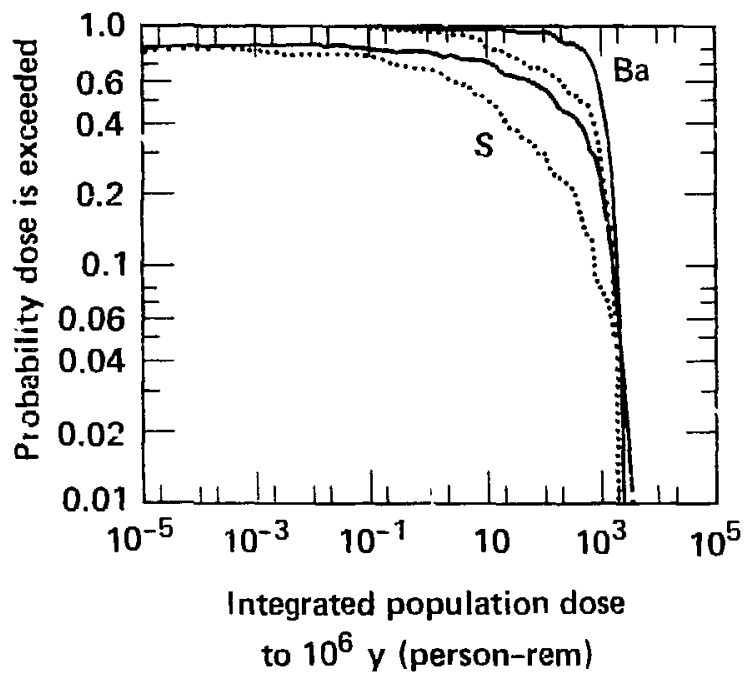

(B)

Figure 14. Comparison of ALTERNATIVE (dotted lines) and REFERENCE (solid lines) risks for basalt (Ba) and layered-salt (S) repositories. Figure $A$ is the AEI peak dose rate, and Figure $B$ is the CRP6 dose.
Contrary to the trend for the AEI dose, the LI dose for basalt is substantially lower than that for : alt (see Fig. 15). A BASALT/LI/90CL dose reduction 4 orders of magnitude (from abou 200 $\mathrm{mrem} / \mathrm{y}$ at the $90 \mathrm{CL} / \mathrm{SA} \mathrm{LT}$ to $0.04 \mathrm{mrem} / \mathrm{y}$ for $90 \mathrm{CL} / \mathrm{BASALT}$ ) in basalt is due to slower migration of much of the waste and water through the rock above the storage area. Hence, in the case of basalt, less radioactivity flows up the shafts and, in many more cases, water flows down the shafts. Thus, we get substantially lower LI/BASALT doses.

\section{Alternative Design}

In situations where the waste forms dissolve fairly rapidly, it has been shown that design feasures can have a strong effect on near-field dose;. To analyze the possible effects of design on predicted doses, we have calculated the doses with a hydraulic bypass as shown in Fig. 16. The development of an uptimum design was not completed for this analysis. The effects of the bypass on the AEI and CRP6 doses were relatively large (see Table 4). It also had major effects on some oliner performance measures. For example, it drastically changed the flow patterns in the system.

We chose a bypass just below the salt layer as show'n in Fig. 16. The mined configuration is shown in the plane view of the bypass horizon. It consists of 23 storage-like drifts running along the direction of the horizonta' regional flow gradient. The side view shows that the upstream side of the bypass starts to the left of the return air shaft and is located $120 \mathrm{~m}$ below the storage area. It ext inds for $100 \mathrm{~m}$ beyond the storage area and discharges into seven vertical shafts with an area of $100 \mathrm{~m}^{2}$ each.

For water originally in the storage room to get to the bypass requires that it flow through at least $100 \mathrm{~m}$ of salt barrier, either horizontally out the end of the storage area or downward to the bypass. The bypass width is the same as the storage area shown in Fig. 5. Thus, nearly all upward flow

Table 3. Comparison of waste form release rates for alternative sites.

\begin{tabular}{|c|c|c|c|c|c|}
\hline \multirow[b]{2}{*}{ Waste form } & \multirow[b]{2}{*}{ Site } & \multicolumn{2}{|c|}{ AEI $(\mathrm{rem} / \mathrm{y})$} & \multicolumn{2}{|c|}{ CRP6 (person-rem) } \\
\hline & & $\mathrm{BE}$ & $90 \mathrm{CL}$ & $\mathrm{BE}$ & $90 \mathrm{CL}$ \\
\hline REFERENCE & $\begin{array}{l}\text { SALT } \\
\text { BASALT }\end{array}$ & $\begin{array}{l}6 \times 10^{5} \\
1 \times 10^{3}\end{array}$ & $\begin{array}{l}1 \times 10^{2} \\
4 \times 10^{2}\end{array}$ & $\begin{array}{l}2 \times 10^{2} \\
1 \times 10^{3}\end{array}$ & $\begin{array}{l}2 \times 10^{3} \\
2 \times 10^{3}\end{array}$ \\
\hline ALTERNATIVE & $\begin{array}{l}\text { SALT } \\
\text { BASALT }\end{array}$ & $\begin{array}{l}2 \times 10^{6} \\
1 \times 10^{4}\end{array}$ & $\begin{array}{l}1 \times 10^{-3} \\
1 \times 10^{-2}\end{array}$ & $\begin{array}{l}1 \times 10^{1} \\
5 \times 10^{2}\end{array}$ & $\begin{array}{l}8 \times 10^{2} \\
2 \times 10^{3}\end{array}$ \\
\hline
\end{tabular}


Table 4. Comparison of REFERENCE and ALTERNATIVE waste form for alternative designs.

\begin{tabular}{|c|c|c|c|c|c|}
\hline \multirow[b]{2}{*}{ Waste form } & \multirow[b]{2}{*}{ Uesign } & \multicolumn{2}{|c|}{$\operatorname{AEI}(\mathrm{rem} / \mathrm{y})$} & \multicolumn{2}{|c|}{ CRP' (person-rem) } \\
\hline & & $\mathbf{B E}$ & $90 \mathrm{CL}$ & $\mathrm{BE}$ & $90 C l$ \\
\hline RFFERENCE & $\begin{array}{l}\text { W/u BYPASS } \\
\text { BYPASS }\end{array}$ & $\begin{array}{r}6 \times 10^{=} \\
1 \times 10^{1}\end{array}$ & $\begin{array}{l}1 \times 10^{2} \\
2 \times 10^{4}\end{array}$ & $\begin{array}{l}2 \times 10^{2} \\
\because 1 \times 10^{7}\end{array}$ & $\begin{array}{l}2 \times 10^{3} \\
2 \times 10^{1}\end{array}$ \\
\hline AI TERNATIVE & $\begin{array}{l}\text { W/O BYPASS } \\
\text { BYPASS }\end{array}$ & $\begin{array}{l}2 \times 10^{1} \\
1 \times 10^{2}\end{array}$ & $\begin{array}{l}1 \times 10^{3} \\
3 \times 10^{5}\end{array}$ & $\begin{array}{r}1 \times 10^{1} \\
\therefore 1 \times 10^{7}\end{array}$ & $\begin{array}{l}8 \times 10^{2} \\
2 \times 10^{0}\end{array}$ \\
\hline
\end{tabular}

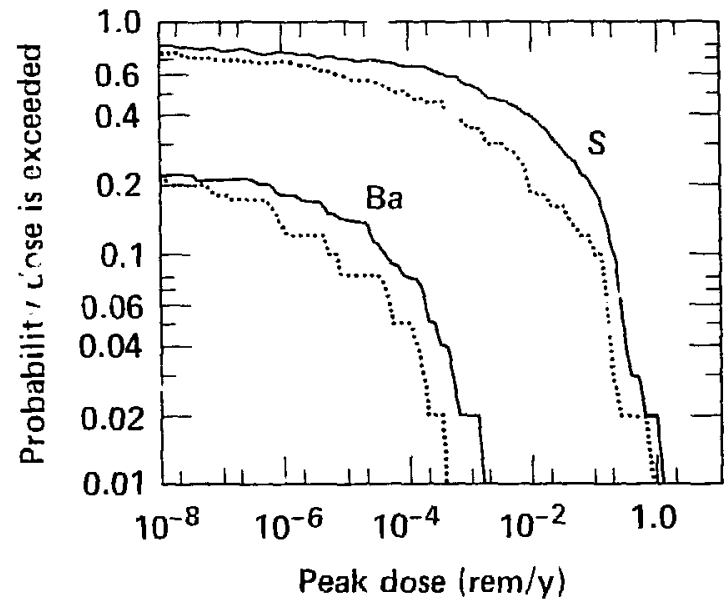

Figure 15. Comparison of LI peak dose rates for basalt (Ba) and layered-sa!t (S) repositories. frc: $n$ the lower aquifer will be intercepted by the by pass before it gets to the defense HLW storage area.

The permeability and effective porosity of the bypass is that of gravel. This choice effectively eliminates all upward fow of nuclides in the shafts. It causes a downward or horizontal (leftto-right) flow through the repository to the bypass for all Monte Carlo trials. This increases the time of intial radionuclide emergence at the $A E I$ well from 6.(10) to about ane million years for the median ialue rase, thus, keeping hazartous material confined to the repository for much longer timis. The flow patterns observed when the bypass is included is roughly shown by arrows in Fig. 16. The flows in the shafts for the hasecase (without BYPASS) are nearly always in the opposite direction.

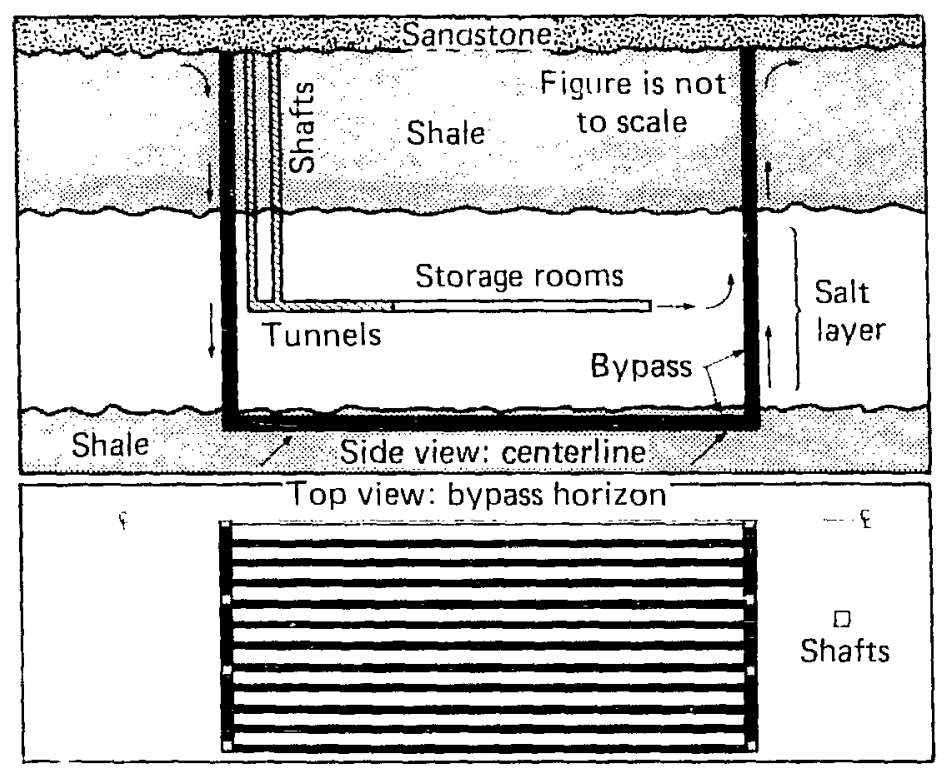

Figure 16. Layout of hydraulic bypass used in alternative design scenario. The arrows indicate the direction of flcw when the bypass is used. These flows are signifirantly different than those shown in Fig. 1. 


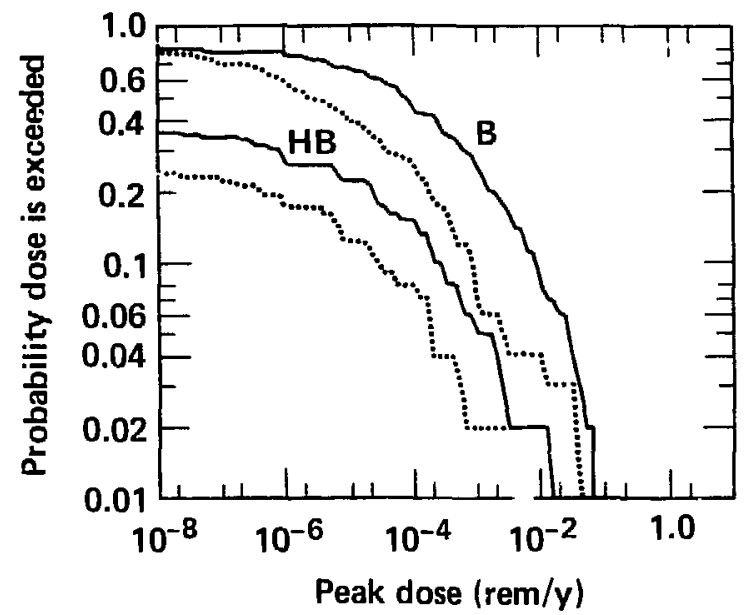

(A)

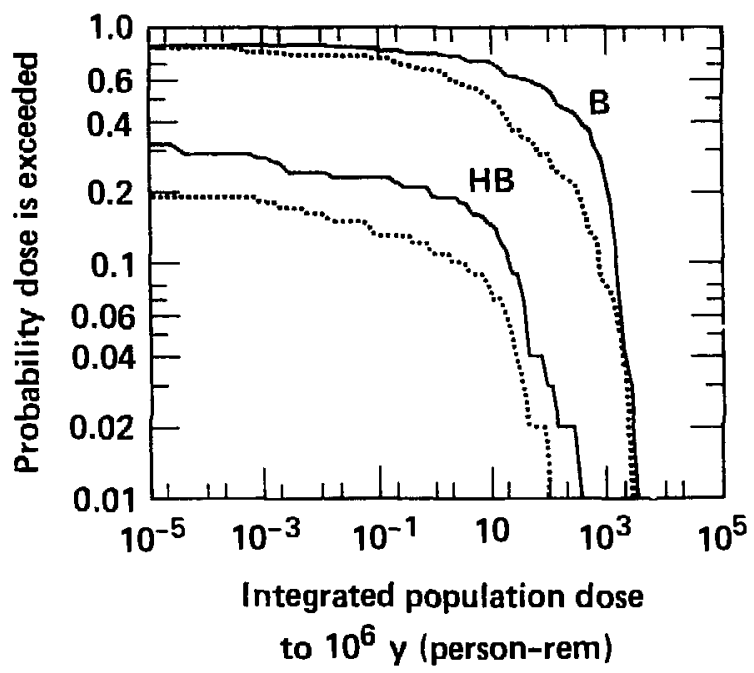

(B)

Figure 17. Comparison of REFERENCE (solid line) and ALTERNATIVE (dotted line) for basecase (B) and hydraulic bypass (HB) designs in bedded-salt repository. Figure $A$ is AEI peak dose rate. Figure $B$ is CRP6 dose.

Results. In Figs 17A and $\mathrm{B}$, we see that the dose is reduced by a factor of at least 10 for all confidence levels below $95 \mathrm{CL}$ when the hydraulic bypass is in place. AEI and CRP6 doses were observed only in $30 \%$ to $35 \%$ of the trials when the bypass was included in the repository design. Thus, the "best-estimate" dose for both REFERENCE and ALTERNATIVE is zero.

With the bypass on, there is about a factor of 50 reduction in individual dose at the high-dose side of the curve for AEI/REFERENCE. When $B Y$ PASS is on, changing to ALTERNATIVE does not improve the predicted $A E I$ dose at the $50 C L$. It improves the $A E I$ dose rate by $0.2 \mathrm{mrem} / \mathrm{y}$ at the $90 \mathrm{CL}$. As one moves to lower confidence levels, the percentage of reduction in dose over the basecase (without BYPASS) becomes very large. For example, at the $50 \%$-confidence level, this factor is unbounded.

The BYPASS-without-ALTERNATIVE design improves the basecase performance, both for $A E l$ and CRP6, by a factor of better than 5 more than the ALTERNATIVE-without-BYPASS design.

Including both the BYPASS and improved waste form (i.e., BYPASS/ALTERNATIVE) decreases the BYPASS/REFERENCE dose at the high-confidence levels by about a factor of 5 .

Improvements in the population dose integrated for one million years are substantial. At $50 \mathrm{CL}$, the improvement is at least a factor of $10^{8}$ for both waste forms. At the $90 \mathrm{CL}$, it is an improvement of 100 for REFERENCE and 400 for ALTERNATIVE. This can be compared with a reduction in CRP6/90CL dose of only two when the improved waste form is used without a bypass.

The derived population dose benefit obtained from changing to ALTERNATIVE is zero at $50 C L$ and anly 18 person-rem at $90 \mathrm{CL}$ when there is a bupass.

Another interesting observation, which is not strongly sensitive to model assumptions, is that the $L I$ dose was zero for all trials when there was a bypass. This is caused by water flowing down the shafts for every Monte Carlo trial when the bypass was part of the design. Upward flow in the shafts occurs about $80 \%$ of the time for the basecase. When the flow is downward, $\mathrm{LI}$ receives no dose because the LI well is downstream of the shafts, but upstream of the storage areas.

\section{Disruptive Events}

To determine the magnitude of the hazard if future disruptive events occur, we have examined events in our basecase salt repository, which we consider both sufficiently probable and also likely to lead to high doses. These events must disrupt the flow system enough to cause significantly higher doses than those of the uneventful scenario. There are, of course, very low probability scenarios that could lead to high consequences. There is, for example, a meteorite direct hit. This, however, has such a low probability of occurrence, i.e., a $0.1 \%$ chance during a time period approxinating the age of the earth, that its risk is considered negligible. ${ }^{13}$ Another type of uninteresting scenario, for example, is the repository site receiving a substantially large rainfall, say 
twice seasonal average in the next $10,000 \mathrm{y}$. This has a high probability of occurrence, but its impact on the long-term hydrology would be insignificant. Thus, the consequences will lead to no effective change in the results from the uneventfui scenario. Numerically, we handle this as an uneventful scenario.

The scenarios we feel are important in our first-order uncertainty analysis are a fault, a failed (i.e., a future drilling or undetected) borehole, ${ }^{*}$ deteriorated backfill, and breccia pipe formation,

Our approach has been to choose what we consider to be conservative assumptions to make the scenarios consistent with our modeling approximations, i.e., the event occurs early by $1000 \mathrm{y}$ after closure. This should lead to worse consequences than if the event were to occur at late times. The second assumption is that we have chosen the event to occur at a particularly bad location in the repository, i.e., at the downstream

\footnotetext{
"Undetected-flaw scenarios are defined as eventful scenarios. In our steady-state flow model, flaws caused by future 'vents and undetected flaws are treated in the same manner, i.e., as though they existed from the time of closure.
}

edge of tile repository (see Fig. 18). This produces flow so that recharge is more likely from both the lower aquifer and the shaft into the excavation. On the average, this should lead to larger flow speeds and more radionuclides moving through the flow path than at upstream locations. There will, however, be sets of parameters that might lead to individual trials with worse results for upstream locations and different event times. Analyzing all possibilities is beyond the scope of this work. A third assumption is that if a flaw occurs at more than $10,000 \mathrm{y}$ after closure, its effect on waste migration is insignificant. This assumption is useful numerically, and is consistent with the $10,000-y$ period of interest dictated by EPA and NRC draft policy statements.

Figure 19 sho's the cumulative distribution functions for the disruptive event scenarios for the AEI dose. Table 5 summarizes these results. We see that, at the $90 \%$ level of confidence, the maximum increase in dose to AEI/REFERENCE is no move than an order of magnitude above the uneventful case. This occurs for fault slippage, which has a fairly low probability of occurrence.

For the $90 \mathrm{CL}$. the deteriorated backfill and the breccia pipe consequences lead to doses about

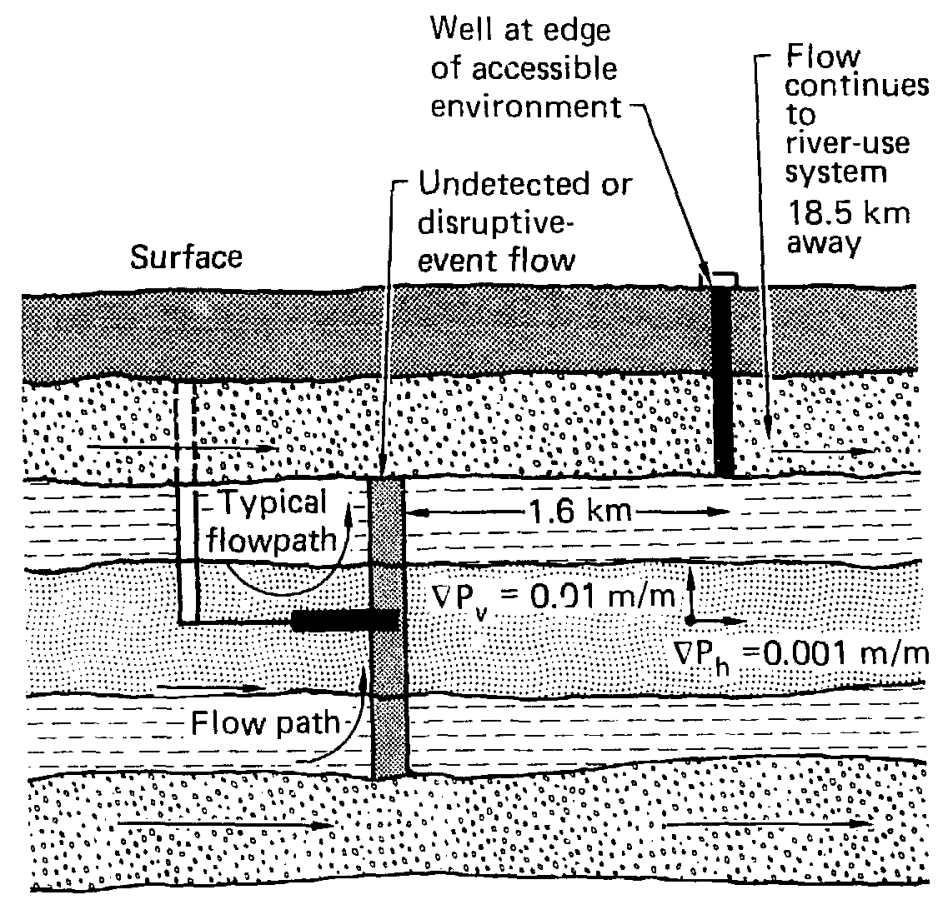

Figure 13. Disruptive event scenario. The flaw is located at the downstream edge of the repository, thus providing an easy flow path to the aquifer. 


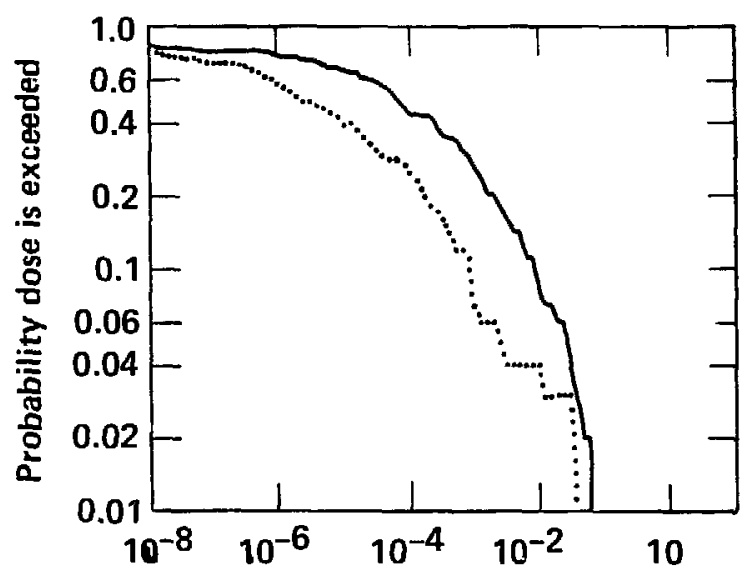

(A) Uneventful AEI peak dose (rem/y)

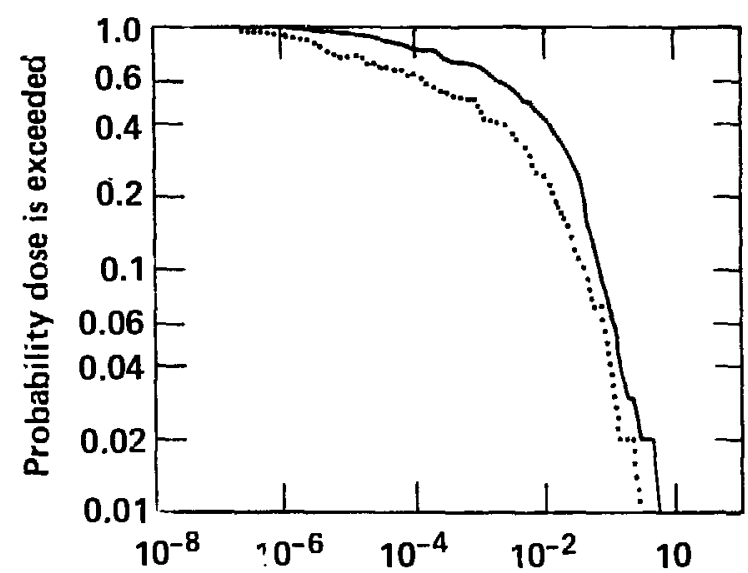

(C) Failed borehole AEI peak dose (rem/y)

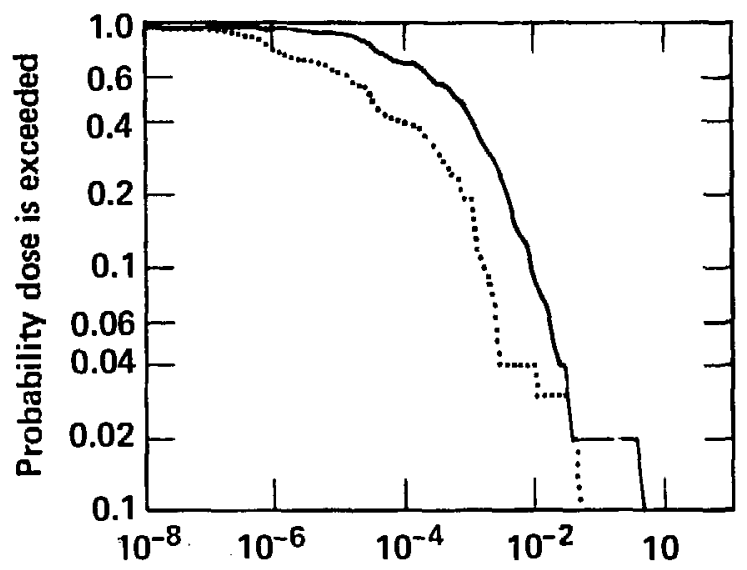

(E) Breccia pipe AEI peak dose (rem/y)

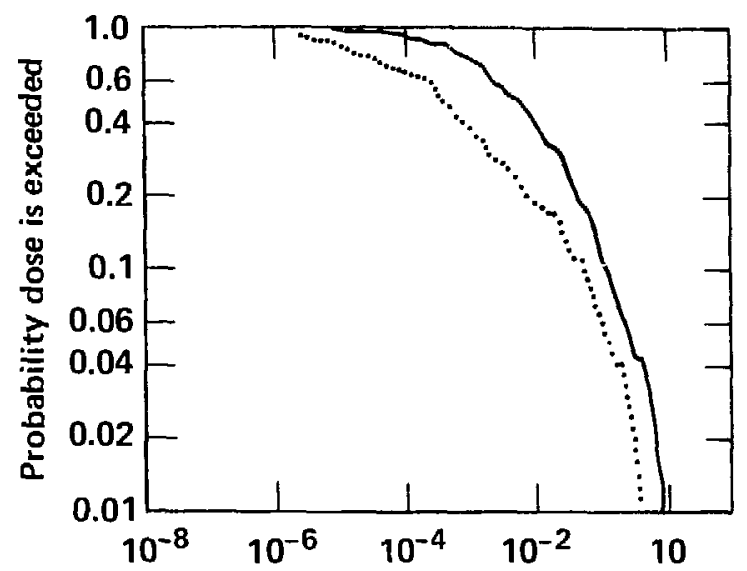

(B) Slipped fault AEI peak dose (rem/y)

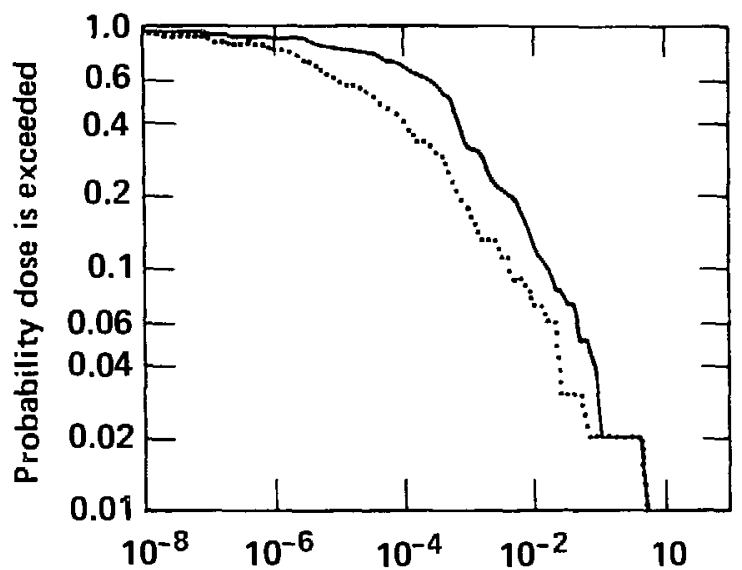

(D) Deteriorated backfill AEI peak dose (rem/y)

Figure 19. Comparison of the eventful and uneventful AEI risk curves. REFERENCE and ALTERNATIVE waste forms are solid and dotted lines, respectively. The figures are results from scenarios: (A) unzventful; (B) slipped fault; (C) failed borehole; (D) deteriorated backfill; and (E) breccia pipe formation. 
Table 5A. Eventful scenaric "best-estimate" doses.

\begin{tabular}{|c|c|c|c|c|c|c|}
\hline & & Uneventfu] & Fault & Borehole & $\begin{array}{c}\text { Deferiorated } \\
\text { backfill }\end{array}$ & $\begin{array}{c}\text { Breccia } \\
\text { pipe }\end{array}$ \\
\hline $\mathrm{AEl}$ & REFERENCE & $6 \times 10^{5}$ & $6 \times 10^{3}$ & $5 \times 10^{3}$ & $6 \times 10^{4}$ & $3 \times 10^{4}$ \\
\hline$(\mathrm{rem} / \mathrm{y})$ & ALTERNATIVE & $2 \times 10^{6}$ & $4 \times 10^{4}$ & $0 \times 10^{4}$ & $3 \times 10^{5}$ & $4 \times 10^{-5}$ \\
\hline CRPG & REFERENCE & $2 \times 1 n^{2}$ & $2 \times 10^{3}$ & $1 \times 10^{3}$ & $1 \times 10^{3}$ & $3 \times 10^{2}$ \\
\hline (person-rem) & ALTERNATIVE & $1 \times 10^{1}$ & $4 \times 10^{2}$ & $4 \times 10^{2}$ & $9 \times 10^{1}$ & $5 \times 10^{1}$ \\
\hline
\end{tabular}

Table 5B. Eventful scenario $90 \%$ confidence level doses.

\begin{tabular}{llccccc}
\hline & & & & & Deteriorated & $\begin{array}{c}\text { Breccia } \\
\text { pipe }\end{array}$ \\
\hline bEI & UEFkfill & Eneventful & Fault & Borehole & $1 \times 10^{2}$ & $1 \times 10^{2}$ \\
$(\mathrm{rem} / \mathrm{y})$ & ALTERNATIVE & $1 \times 10^{3}$ & $6 \times 10^{2}$ & $4 \times 10^{2}$ & $2 \times 10^{3}$ & $5 \times 10^{3}$ \\
CRPG & REFERENCE & $2 \times 10^{3}$ & $3 \times 10^{3}$ & $3 \times 10^{3}$ & $2 \times 10^{3}$ & $2 \times 10^{3}$ \\
(person-rem) & ALTERNATIVE & $8 \times 10^{2}$ & $2 \times 10^{3}$ & $3 \times 10^{3}$ & $2 \times 10^{3}$ & $9 \times 10^{2}$ \\
\hline
\end{tabular}

the same as the uneventful case for the REFERENCE waste form and AEI individual. This is due to the highel effective porosities for the deteriorated backfill, which lead to slower migration rates than the uneventful case, even though the permeability is higher. The borehole produces high velocities and is r"charged by large amounts of water in the system.

In Table 5, the largest BE/AEI/EVENTFUL dose is only $6 \mathrm{mrem} / \mathrm{y}$. This $\mathrm{i}$, over an order of magnitude below background. Our highest $90 \mathrm{CL}$ dose is only about background radiation. This occurs for a low probability event, i.e., fault slippage. For the borehole ca'se, we have conservatively assumed that it intersects a storage room and not a pillar. The storage room penetration leads to a higher dose but the likelihood of its intercepting a storage room is only $1 / 3$ as high as that for a pillar.

The largest population dose (90CL/ REFERENCE) is 3000 person-rem from a slippedfault scenario. This is only $150 \%$ of the uneventful case dose. It is an insignificant population dose when compared with any other measure of risk. Over a one-million-vear disposal period, the repository has about a $50 \%$ probability of producing a single premature cancer, even if fault slippage occurs soon after closure.

The risk from all the important scenarios can be incorporated into a single probabilistic curve, which provides a single measure of performance. The information necessary for this curve is the probability for the occurrence of each of the sce- narios, an assumption that the probability of two events occurring is much smaller than one, and the choice of a representative disruptive-event set of parameters for each class of scenarios.

Since we are doing a first-order uncertainty study (and we consider the introduction of the disruptive-event scenarios as a first-order correction of the uneventful consequence analysis), we have the probability of the event to occur (e.g., occurrence per year at the site) as our first-order uncertainty associated with that scenario. Incorporating an uncertainty on the rate of occurrence would lead to a second-order uncertainty analysis, which would clearly test our computational capabilities and would be unlikely to change our results significantly.

The disruptive-event scenarios we have considered for bedded salt are deteriorated backfill, failed borehole, fault slippage, and breccia pipe formation.

- For deteriorated backfill, we have reviewed the literature and found a large probability of occurrence (in Ref. 19). Other studies ${ }^{20}$ have been less pessimistic and, in fact, have not even considered this event important enough to incorporate in their findings on scenario analysis. We feel that we are being conservative by choosing a probability of occurrence of 0.2 in 10,000 $\mathrm{y}$.

- For failed borehole scenarios, we have used values obtained from Ref. 13. Here we are looking at several physical situations. The first is that of the boreholes, which have been drilled to explore site characteristics. This might lead to seal 
failure. The second is undetected boreholes from previous exploration for resources. The third is future inadvertent drilling. Reference 13 gives values of $10^{-5}$ for an undetected borehole. Careful policy should restrict site exploration damage to zero. Under loss of administrative control they have given a probability of $10^{-2}$ during the first $200 \mathrm{y}$ for future drilling. If one assumes this rate as constant for $10^{4} y$, the probability of at least one drill hole occurring in a bedded salt repository is 0.4. Since their analysis was for a several times larger repository area, we have chosen 0.1 as our estimate of a failed borehole (i.e., a future drilling).

- Faulting is given by various studies ${ }^{19,20}$ as having a probability in 10,000 $\mathrm{y}$ from a high of $5 \times 10^{-3}$ to $10^{-6}$. We choose a conservative order-of-magnitude estimate of $10^{3}$. We also assume that once the fault opens, it remains open for the duration. This is probably not the case, but it is conservative and allows the computation to be done with a steady-state model.

- Breccia pipe formation is estimated ${ }^{13}$ to occur in bedded salt with a frequency of about $10^{-8} / \mathrm{y}$. Thus, for $10,000 \mathrm{y}$, we get approximately a $10^{+4}$ probability of occurrence.

Table 6 summarizes the rates used in calculating the probability of seeing a particular scenario in the next $10,000 \mathrm{y}$. These lead to the curves shown in Fig. 20. The curve can be read, for example, as a model prediction that there is a $0.01 \%$ chance of seeing a dose greater than $130 \mathrm{mrem} / \mathrm{y}$ from a fault slippage at the site for a REFERENCE waste form. Thus, we believe with $99.99 \%$ confidence level that not more than $130 \mathrm{mrem} / \mathrm{y}$ will be received by AEI from a future fault-slippage scenario with REFERENCE waste form.

When we sum the effects of ail the scenarios, we ge: the curves for REFERENCE and ALTERNATIVE shown as total risk. We predict with $90 \%$ confidence that the future AEI/ALTERNATIVE dose will be below 3 mrem/ $y$. This is a factor of 30 below background radiation.

Finally, Fig. 21 compares the total risk curve with the curve we would get if we assumed that

Table 6. Scenario probabilities.

\begin{tabular}{lc}
\hline \multicolumn{1}{c}{ Scenario } & Rate of occurrence \\
\hline Deteriorated backfill & $2 \times 10^{7} / y$ \\
Failed borehole & $1 \times 10^{5 / y}$ \\
Faulting & $10 \% / y$ \\
Brecria pipe formation & $10 \% / y$ \\
\hline
\end{tabular}

all future disruptive events lead to insignificant changes in the system hydrology. Table 7 is extracted from Fig. 21 to compare BE and $90 \mathrm{CL} A E l$ doses for both waste forms for the disruptiveevent and basecase scenarios. One can see for a given confidence level that there is very little change in the cumulative distributions. This implies that the major risk sensitioities in a permeable layered-salt system are due to inability to measure and predict the process of a gizen scenario, not the cffects of disruptize cuents. Thus, we could have arrived at excellent approximations without a very careful scenario analysis. Excavation parameters and dynamic processes are the most important considerations in our forecasts.

\section{Alternative Criteria}

The curve labeled $10^{4}$ in Fig. 22B shows the population dose accumulated to $10,000 y$ after closure (the time frame of interest to NRC and EPA). For this performance measure, only $29 \%$ of the samples had sufficient transport velocity to lead to a measurable population dose. The best-estimate dose is zero. The 90th-percentile dose is an extremely small 0.2 person-rem in $10^{4} \mathrm{y}$. This population dose is about what one person receives from natural background radiation in one year.

The 10 curve is but one of many different performance measures that can be devised for a repository system. No definitive national standard exists with which forecasts can be unequivocally compared. Traditional standards have been cast into two types: the first rrotects the individual. and thus the local envirc iment; the second type protects the population and is more global in nature. In developing our capability, we have considered both types of results.

There are several locations where it seems reasonable to forecast the individual dose. In our scenario, fresh water is available from the upper aquifer. We thus chose three different locations leading to the $\mathrm{LI}, \mathrm{AEl}$, and CRI doses. The first duse is from a well just downstream from the shafts. The secorid is a well $1.6 \mathrm{~km}$ from the repository edge and the third is an average individual who lives in the Columbia River water use svstem. Figure 22A compares these individual REFERENCE and ALTERNATIVE doses for our basecase.

From Fig. 22A, it is obvious that the choice of performance measure can greatly influence the predicted level of dose. The peak dose ranges from 5 to 6 orders of magnitude, between the CRI and LI doscs. For comparison, the difference between using different waste forms is only about a factor of 


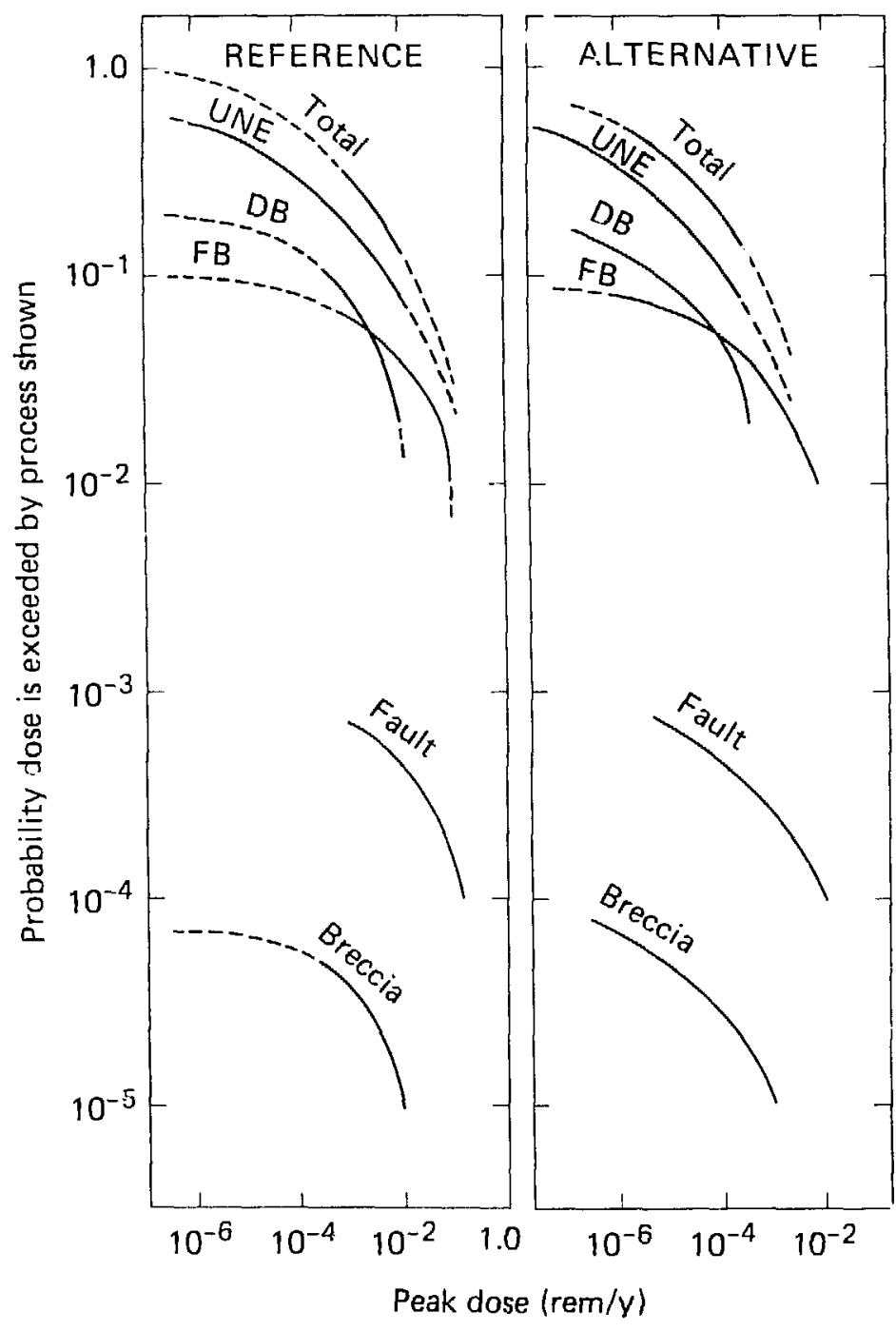

Figure 20. Scenario of normalized eventful AEI risk curves and total risk for REFERENCE (LHS) and ALTERNATIVE (RHS). DB, FB, and UNE stand for deteriorated backfill, failed borehole, and uneventful, respectively.

Table 7. AEI dose comparison of waste forms for eventful and uneventful scenarios (rem/y).

\begin{tabular}{|c|c|c|c|c|}
\hline \multirow[b]{2}{*}{ Waste form } & \multicolumn{2}{|c|}{ Uneventful } & \multicolumn{2}{|c|}{ Eventful } \\
\hline & $\mathrm{BE}$ & $90 \mathrm{CL}$ & $\overline{B E}$ & $90 \mathrm{CL}$ \\
\hline REFERENCE & $6 \times 10^{5}$ & $1 \times 10^{2}$ & $2 \times 10^{4}$ & $2 \times 10^{2}$ \\
\hline ALTERNATIVE & $2 \times 10^{b}$ & $1 \times 10^{3}$ & $8 \times 10^{11}$ & $3 \times 10^{3}$ \\
\hline
\end{tabular}




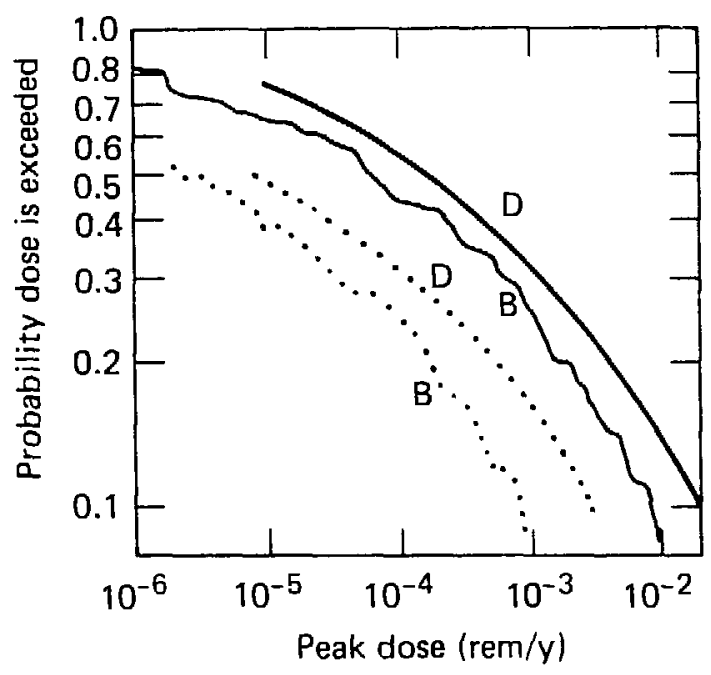

Figure 21. Comparison of basecase (B) and disruptive-event (D) risk curves for REFERENCE (solid line) and ALTERNATIVE (dotted line).

10 for LI. It is reassuring to note that the largest $B E$ peak individual dose using any of the performance measures is only $2 \mathrm{mrem} / \mathrm{y}$. At the $90 \%$ confidence level, the LI dose rate is $200 \mathrm{mrem} / \mathrm{y}$. For the ALTERNATIVE/AEI/90CL case, we have $1 \mathrm{mrem} / \mathrm{y}$. For REFERENCE/CRI/90CL, we forecast $2 \times 10^{4} \mathrm{mrem} / \mathrm{y}$ (about one-millionth of background radiation).

We see for the highest doses that the ALTERNATIVE waste form is not especially effective in lowering dose rate (cf. the LI/90CL dose rates). ALTERNATIVE does, however, reduce doses by about a factor of 10 for all the performance measures below the $80 \mathrm{CL}$. If we introduce a bypass in the design, the LI dose rate becomes zero and the AEII $90 C L$ dose rate is reduced by a factor of 50 . Since the $\mathrm{AEI}$ dose rate is less sensitive than the LI dose to alternatives like the bypass, it is the more robust performance measure. It also is closer to the prescription for performance assessment given in drait 40CFR191 than the LI performance measure.

Choosing a population risk measure is as difficult as picking an individual dose measure. Figure $22 \mathrm{~B}$ shows three integrated dose periods. The $10^{4}-\mathrm{y}$ dose curve is the one apparently favored by EPA. With our system parameters, the $10^{4}-y$ integrated population dose only measures the unreliable front end of the radioactive pulse. This results in CRP4 doses being 4 orders of magnitude below the $10^{5}$ - and $10^{6}-\mathrm{y}$ doses. CRP4 is essentially dealing with model noise. Thus, we have

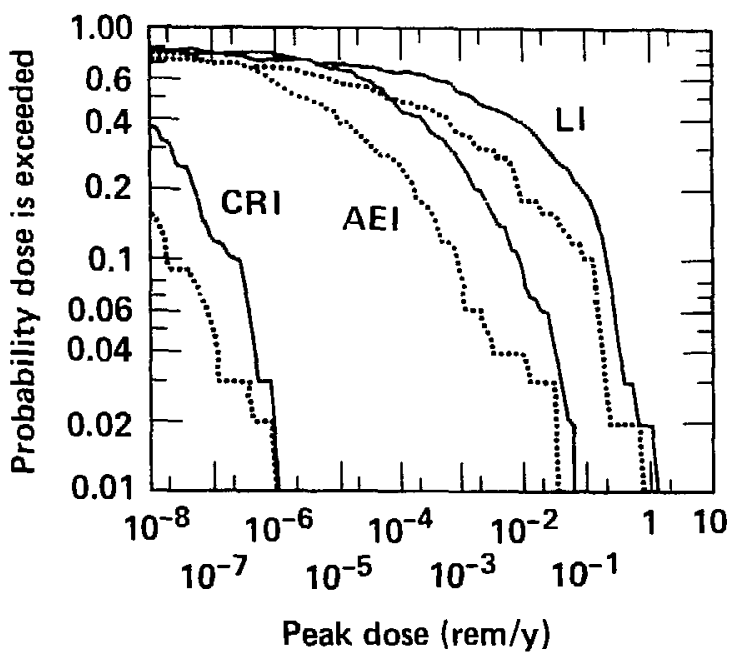

(A)

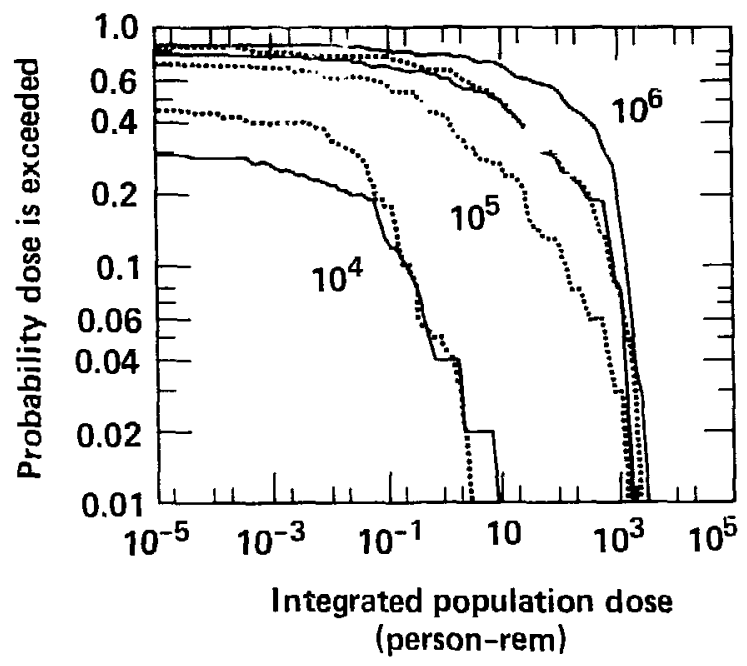

(B)

Figure 22. Comparison of effects on risk curves of different potential safety standards. Figure $A$ shows the effects on individual peak dose of locating the "observation" point at different places. Figure $B$ displays the effects of changing the period over which the population dose is integrated.

used the more reliable $10^{6}-y$ integrated dose as our conservative population dose performance measure.

In Fig. 22B, we note that there is little difference at 90CL for the $10^{5}$ - and $10^{6}$-y integration periods. There is also no major improvement in the $10^{6}-y$ integrated dose if ALTERNATIVE is 
used instead of REFERENCE. The dose is more sensitive to waste form at $90 \mathrm{CL}$ if a $10^{5}-\mathrm{y}$ integration period is used. The largest integrated dose in Table 8 is below the dose that would be expected to lead to one premature cancer death, whether REFERENCE or ALTERNATIVE is used.

\section{Release Rates and Uncertainties}

Our choice of release rates and their uncertainties (as represented by the median and geometric standard deviation of a lognormal distribution) is an important consideration for the purpose of this paper. Thus, we have studied the effects of our choices of these parameters. We use waste form release rates and uncertainties different from our basecase, REFERENCE, and our improved waste form, ALTERNATIVE, to see how this affects repository safety. This takes the form of a sensitivity study over median release rate (U) from $10^{-8} / y$ to $10^{-3} / y$, and for geometric standard deviation $(S)$ representing uncertainties of 10 and 100.
For $U=10^{-6} / \mathrm{y}$ and $S=100$, approximately $98 \%$ of the time the sampled release rate would be between $10^{-2} / y$ and $10^{-10} / y$. If $S=10$, then the same percentage of samples would be chosen between $10^{-4} / y$ and $10^{-8} / y$.

In Table 9, we compare our basecase REFERENCE release rate model with one with a factor of 10 larger uncertainty, as modeled by a lognormal distribution with a geometric standard deviation. of 100 . For the basecase, $S$ is 10 . The basecase median release rate is $U=5 \times 10^{-6} / y$. We see for this $U$ that the $90 \mathrm{CL}$ doses are identical for $S=10$ and $S=100$.

For the BE doses, the ratios of basecase doses to "larger uncertainty" doses range from 2 to 10 Thus, for this comparison, we see that the doses are sensitive to uncertainty at the $50 \mathrm{CL}(\mathrm{BE})$, but not at the higher confidence level of $90 \%$.

Figures 25 and 24 show how the $90 \mathrm{CL}, \mathrm{BE}$, and $25 \mathrm{CL}$ change with respect to median release rates. The $S=10$ curves are represented by solid lines and $S=100$ doses by dashed lines. Figure 23 displays $\mathrm{LI}$ and AEI doses. Figure 24 shows the

Table 8. Comparison of REFERENCE and ALTERNATIVE waste forms for alternative criteria.

\begin{tabular}{|c|c|c|c|c|c|c|}
\hline & \multicolumn{6}{|c|}{ Individual dose $(\mathrm{rem} / \mathrm{y})$} \\
\hline & \multicolumn{3}{|c|}{ Best estimate } & \multicolumn{3}{|c|}{$90 \%$ confidence level } \\
\hline & LI & AEI & CRI & LI & AEI & CRI \\
\hline REFERENCE & $2 \times 10^{3}$ & $6 \times 10^{5}$ & $3 \times 10^{-9}$ & $2 \times 10^{1}$ & $1 \times 10^{-2}$ & $2 \times 10$ \\
\hline \multirow[t]{4}{*}{ ALTERNATIVE } & $1 \times 10^{-4}$ & $2 \times 10^{-6}$ & $1 \times 10^{-10}$ & $1 \times 10^{-1}$ & $1 \times 10^{3}$ & $2 \times 10^{8}$ \\
\hline & \multicolumn{6}{|c|}{ Population dose (person-rem) } \\
\hline & \multicolumn{3}{|c|}{ Best estimate } & \multicolumn{3}{|c|}{$90 \%$ confidence level } \\
\hline & $10^{4}$ & $10^{5}$ & $10^{6}$ & $10^{4}$ & $10^{5}$ & $10^{6}$ \\
\hline REFERENCE & $<2 \times 10^{-8}$ & $9 \times 10^{0}$ & $2 \times 10^{2}$ & $2 \times 10^{-1}$ & $9 \times 10^{2}$ & $2 \times 10^{3}$ \\
\hline ALTERNATIVE & $<10^{-4}$ & $4 \times 10^{-1}$ & $1 \times 10^{1}$ & $2 \times 10^{-1}$ & $2 \times 10^{2}$ & $8 \times 10^{2}$ \\
\hline
\end{tabular}

Table 9. Comparison of larger release rate uncertainty with basecase.

\begin{tabular}{|c|c|c|c|c|c|c|}
\hline \multirow{2}{*}{$\begin{array}{l}\text { Release rate } \\
\text { uncertainty }\end{array}$} & \multicolumn{2}{|c|}{$\mathrm{LI}(\mathrm{rem} / \mathrm{y})$} & \multicolumn{2}{|c|}{ AEI $($ rem/y) } & \multicolumn{2}{|c|}{ CRP6 (person-rem) } \\
\hline & $\mathrm{BE}$ & $90 \mathrm{CL}$ & BE & $90 C L$ & BE & $90 \mathrm{CL}$ \\
\hline $\begin{array}{l}\text { Basecase } \\
(S=10)\end{array}$ & $2 \times 10^{3}$ & $2 \times 10^{1}$ & $6 \times 10^{5}$ & $1 \times 10^{-2}$ & $2 \times 10^{2}$ & $2 \times 10^{3}$ \\
\hline $\begin{array}{l}\text { Larger } \\
\text { uncertainty } \\
(S=100)\end{array}$ & $2 \times 10^{4}$ & $2 \times 10^{1}$ & $3 \times 10^{-5}$ & $1 \times 10^{2}$ & $5 \times 10^{1}$ & $2 \times 10^{3}$ \\
\hline
\end{tabular}




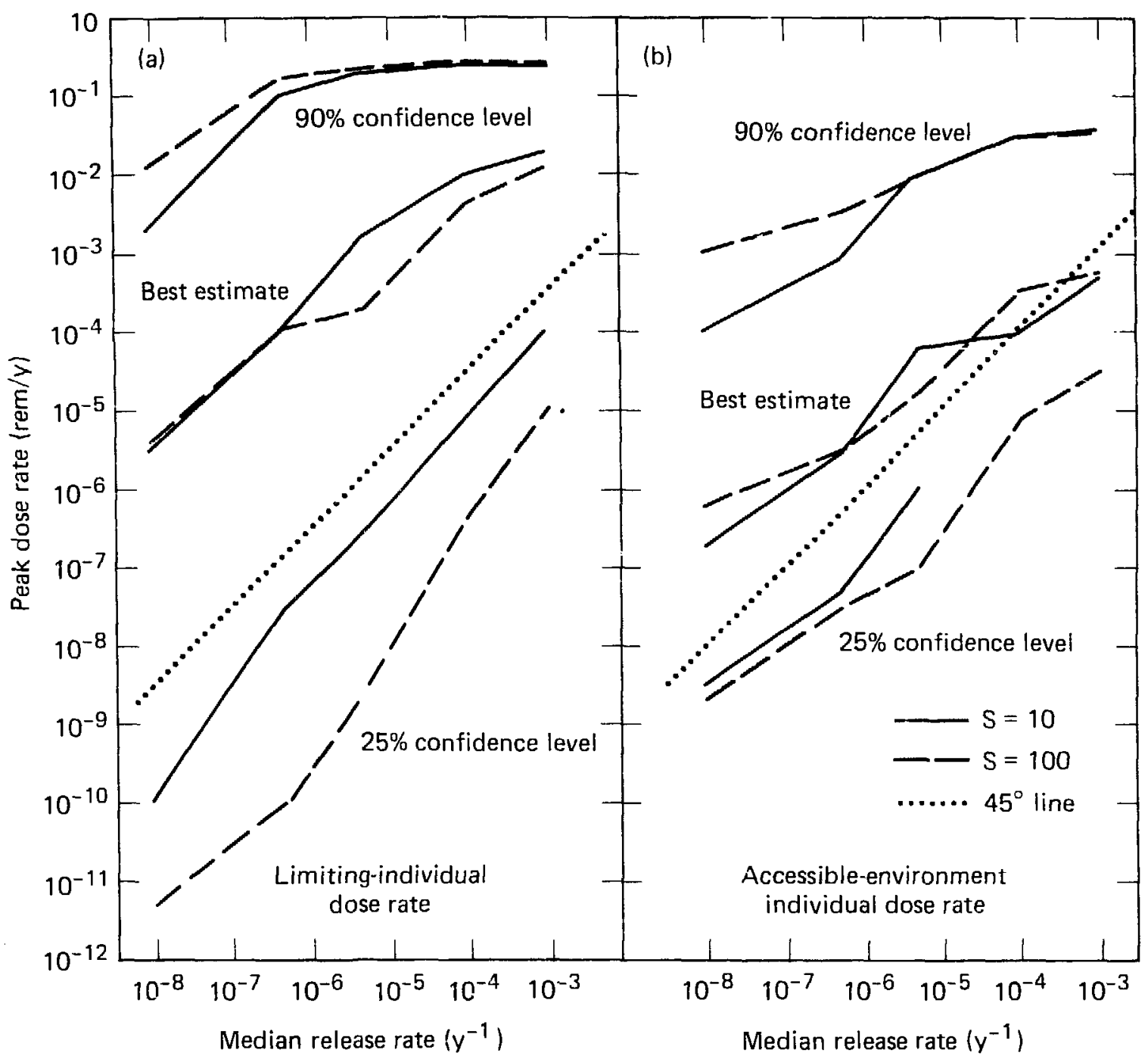

Figure 23. Individual peak dose comparison of varying waste form technology: [The technology improves with a lower median release rate and reduced uncertainty on that release rate.] These curves show the effects on the $90 \%, 50 \%$, and $25 \%$ confidence levels as the release rate is lowered from $10^{-3} / y$ to $10^{-8} / y$. The dashed curve is for a release rate geometric standard deviation of 100 indicating poor understanding of the leaching process. The solid curve is a geometric standard deviation of 10 , which represents a much better understanding of the release rate. The dotted line indicates the slope where a percent change in the release rate leads to an equal percent change in dose.

CRP6 doses. The dotted lines show curves where the percent change of peak dose is equal to the percent thange of median release rate, i.e., if the release rate changes by a factor of 10 , so will the peak dose.

Figure 23 shows that, for the $25 \mathrm{CL}$ and $\mathrm{BE}$ curves, the percent change in dose nearly equals the percent change in median release rate for
$U=10^{-8} / y$ to $10^{-3} / y$. For CRP6, this is true only for median release rates less than $10^{-4} / y$.

For low-dose levels, as depicted by the $25 \mathrm{CL}$ curve in Figs. 23 and 24, the doses are consistent with a model linearly proportional to release rate. Thus, if we were to know the $25 \mathrm{CL}$ dose at, say, $\mathrm{U}=10^{-8} / \mathrm{y}$ and the proportionality constant, we could predict within an order of magnitude, the 


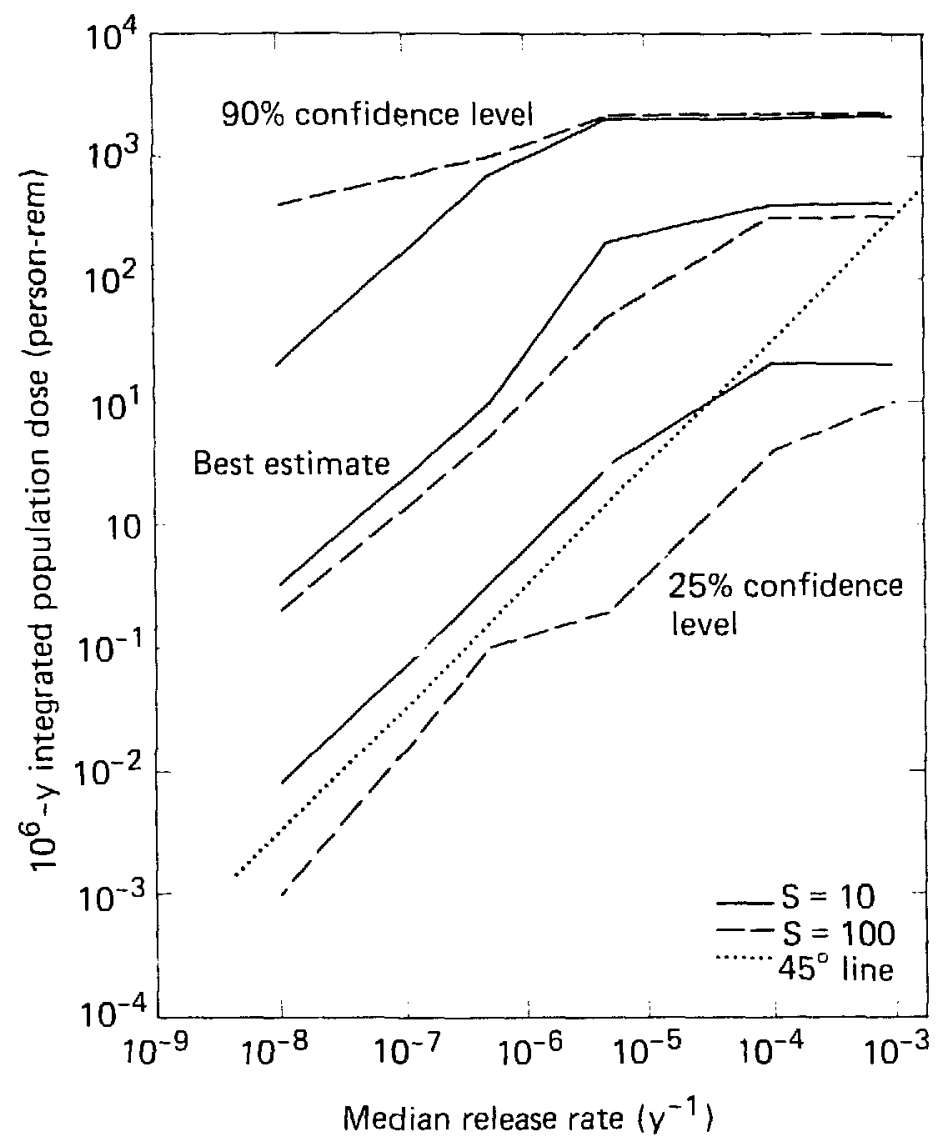

Figure 24. Same as Fig. 23 except that these curves are for population dose.

$25 \mathrm{CL}$ dose at median release rates as high as $10^{3} / \mathrm{y}$. This is true for the BE and $25 \mathrm{CL}$ levels for the individual dose curves. It is also true for the CRP6/25CL and BE curves with $U<10^{-4} / \mathrm{y}$.

For the more important high doses, e.g., the $90 \mathrm{CL}$ dose, the linearity of the doses with respect to median release rate does not occur for $\mathrm{U}>5$ $\times 10^{--i} / \mathrm{y}$. This is best exemplified by the $\mathrm{LI} / 90 \mathrm{CL}$ dose shown in Fig. 23. Above $U=5 \times 10^{-7} / y$ median release rate, the curve is almost flat. Thus, the sensitivity to $U$ is nearly zero in this domain. The sensitivity to $S$ is also nearly zero in this domain, as the $90 \mathrm{CL}$ dashed and solid curves are almost identical.

The same nonlinear effect that occurs for Ll/90CL occurs for all the curves. This effect is nearly as pronounced for the CRP6/90CL (shown in Fig. 24) as it is for LI/90CL. Physically, it is due to dilution factors other than the release rate in the system. These factors are primarily the spacial extension of the repository for the LI doses and the dispersion and retardation for the CRP6 doses. The $\mathrm{BE}$ dose is nearly insensitive to uncertainties for all cases over the full range of $U$.

Improving the median release rate by a factor of 10 tends to improve all doses at each confidence level ( $\leq 90 \mathrm{CL}$ ) by about a factor of 10 for release rates less than $10^{-7} / y$. Doses for confidence levels greater than $90 \%$ will require lower $U$ 's to show dose linearity with respect to $U$. For median release rates of less than $10^{-6} / y$, the uncertainty of the release rate impacts the $90 \mathrm{CL}$ dose, leading to higher dose levels the larger the uncertainty. For sufficiently high confidence levels, or sufficiently high median release rates, the dose is insensitive to uncertainty of the release rate.

Some specific points are

- Improving the median release rate improves doses linearly if the median release rate is 
less than $5 \times 10^{-i} / y$ and thic rnafidence level is less than $90 \%$.

- Reducing release rate uncertainty provides lowered dose at high confidence levels $(\sim 90 \mathrm{CL})$ if the median release rate is less than about $10^{-7} / \mathrm{y}$.

- High dose results cannot be driven higher than those shown in Figs. 23 and 24 by choices of medians and geometric standard deviations representing a worse state of waste form technology. For example, a choice of 1000 for the geometric standard deviation would lead to no more than approximately $30 \mathrm{mrem} / \mathrm{y}$ AEI dose, the same result obtained when $S=10$. This is independent of the median release rate chosen. Better designs or better sires could, however, reduce the $30 \mathrm{mrem} / \mathrm{y}$ AEl dose.
For REFERENCE and ALTERNATIVE, and U's of $5 \times 10^{-6} / y$ and $5 \times 10^{7} / y$, the $90 \mathrm{CL}$ shows almost no sensitivity to uncertainty. For the $25 \mathrm{CL}$, the ratio of doses can be over 100 (as shown in the $\mathrm{LI}$ case). These large sensitivities to the choice of uncertainty are, however, always for low doses, e.g., $10^{-8}$ to $10^{-10} \mathrm{rem} / \mathrm{y}$.

In summary, where the doses are sensitive to the choice of uncertainty, the doses are orders of magnitude below background. Where the doses are significant fractions of background, the sensitivity to release rate uncertainty is nearly zero. Thus, the decision on repository safety should be relatively insensitive with respect to uncertainty on release rate.*

\section{Technical Conclusions}

Unless otherwise indicated, the results in this section are best estimates. In our probabilistic approach, "best estimate" means calculated median dose. In general, we found median dose rates far below natural background radiation levels for peak individual doses and nearly trivial results for iritegrated population doses.

The reduction of these small doses by using an improved ALTERNATIVE waste form instead of REFERENCE (borosilicate glass) is consequently small, even though the reduction at times was greater than an order of magnitude. Where the doses were large in the probabilistic analysis (i.e., at high confidence levels) the effect of changing the waste form to ALTERNATIVE was small. Thus, ironically, for the repository layout chosen where one would hope to gain the most from a better waste form, there seems to be little effect. This indicates that there are other contributing factors for the high confidence level doses which vitiate the effect of release rate.

Some other highlights of the study relevant to a waste form decision are

\section{Basecase peak individual dose.}

- For the layered salt repository with REFERENCE waste form, our "best estimate" of peakequivalent-whole-body dose to an individual using a well located one mile downstream from a repository (the "accessible environment individual "), is about 3 orders of magnitude below background radiation. If the individual puts his well at nearly the worst location possible, right above the repository, he will receive about $1 / 50$ background radiation. If, however, the individual is part of the Columbia River water-use system with an average diet of only contaminated food, he will receive approximately one ten-millionth background radiation. If.we wish to increase our confidence level (from $50 \%$ to $90 \%$ ) that the estimated dose will not be exceeded, then the AEl peak dose inbelow background. The $90 \%$ confidence level dose to the average individual in the CRP system would still be orders of magnitude below background.

- The lower release rate (ALTERNATIVE) waste form improves the peak dose obtained from a well one mile downstream over a factor of 10 for doses below the $70 \%$ confidence level. Above the $90 \%$ confidence level, there is little or no improvement.

Basecase integrated population dose.

- Integrated population dose over the first million years results in a 200 person-rem total dose, less than $1 / 10$ of the dose considered to lead to a single additional premature cancer in the

\footnotetext{
*Another interesting aside on appropriately choosing performance measures would be the case where we use "mean dose" as our measure of performance. If the mean dose were used as a measure of safety, a higher uncertainty on releuse rates would lead to lower mean doses if $L$ was above $10 \% / y$ : Such a choice of performance measure could be misleating to decision makers: i.e.. it would imply larger uncertainty leads to better repository performance.
} 
population. This is our $50 \%$ confidence level eatimate. If we wish to improve our confidence level from $50 \%$ to $90 \%$, we increase the integrated population dose to 2000 person-rem.

- Changing to the improved waste form (ALTERNATIVE) has essentially no effect on the best-estimate integrated population dose (i.e., it reduces the CRP dose by only 190 person-rem in one million years).

Site alternative.

- The basalt repository was a poorer performer (approximately by a factor of 5-50) than the layered-salt repository for the integrated population dose and the peak AEI dose $1.6 \mathrm{~km}$ dounstream. It was a better performer by about a factor of 10,000 for the individual with his well above the repository. Including the bypass in the design reduces the well-above-repository peak dose rate to zero.

- Using the improved waste form (ALTERNATIVE) produces no significant effect on basalt repository performance; i.e., it reduces the AEI dose by $1 \mathrm{mrem} / \mathrm{y}$ and the integrated population dose by 500 person-rem.

Design alternative.

- The bypass increases containment time of initial pulse from $6700 \mathrm{y}$ to approximately one million years for the median value parameters case. Also, at the $90 \%$ confidence level, BYPASS reduces the AEI dose by about a factor of 50 .

- Changing to ALTERNATIVE does not improve performance of repository with BYPASS at the $50 \%$ confidence level. Even at the $90 \%$ confidence level improvement in performance is insignificant (AEI dose by $0.2 \mathrm{mrem} / \mathrm{y}$ and integrated population dose by 18 person-rem).

\section{Release rates and uncertainties.}

- The low-dose ends of the dose vs release rate curves are sensitive to both release rate and releasf: rate uncertainty. Also, the high-releaserate ends of these curves for high ( $90 \%)$ confidence ievels are insensitive to release rate and release rate uncertainty. This is true for release rates greater than approximately $5 \times 10^{-i} / y$.

- The choice of waste form should not be affected by the uncertainty of the waste form release rate. Where the doses are sensitive to uncertainty, the doses are orders of magnitude beiow background. Where the doses are significant fractions of background, they are insensitive to uncertainty of the waste form release rate.

\section{Other conclusions.}

- Changing the location of the calculation of peak dose rate can lead to a change of several orders of magnitude in calculated risk.

- Incorporating possible flaws or disruptive events into the analysis changed the best estimates of the peak individual dose rate by a factor of 3 (a small change since the factor between the $50 \%$ and the $90 \%$ confidence level is 100 ).

- The BYPASS-without-ALTERNATIVE design is a better performer than the ALTERNATIVE-without-BYPASS design by a factor of more than 5 . 


\section{References}

1. Report to the President, Interagency Review Group on Nuclear Waste Management, 1978, Washington, D.C. (1979).

2. H. Cheung, L. L. Edwards, T. F. Harvey, D. D. Jackson, M. A. Revelli, Nuclear Waste Form Assessment for U.S. Defense Waste at Savannah River Plant, Annual Report, Fiscal Year 1981, Lawrence Livermore National Laboratory, Livermore, CA, UCRL-53188-81 (1982).

3. L. L. Edwards and T. F. Harvey. A High-Level Waste-Repository Excavation Model and Limiting Individuai Dose, Lawrence Livermore 'National Laboratory, Livermore, CA, UCRL-86849 (1981).

4. I. Remson, S. J. Dreiss, and A. G. Journel, "Radioactive-Waste Disposal-An Application of Predictive Geology," in Predictive Geology with Emphasis on Nuclear Waste Disposal. C. De Marsily and D. F. Merriain, Eds. (Pergamon Press, NY, 1982) pp. 25-32.

5. P. F. Ricci, and L. S. Molton, "Risk and Benefit in Environmental Law," Science 214, Dec. (1981).

6. T. H. Gould, Savannah River Laboratory, Aiken, SC, private communication (May 23, 1980).

7. M. J. Bell, ORIGEN-The ORNL Isotope Generation and Depletion Code, Oak Ridge National Laboratory, Oak Ridge, TN, ORNL-4628 (1973).

8. T. H. Gould, Savannah River Laboratory, Letter, private communication (January 22, 1982).

9. T. G. Naymik, and L. D. Thorson, Numerical Simulation of Transport in a Regional Groundwater Flow System, Lawrence Livermore National Laboratory, Livermore, CA, UCRL-52556 (1978).

10. G. E. Raines, "Development of Reference Repository Conditions," in Proceedings of the 1980 National Waste Terminal Storage Program Information Meeting, Office of Nuclear Waste Isolation, Columbus, OH, ONWI-212 (1980) pp. 310-315.

11. Nuclear Waste Isolation Activifies Report, Office of Nuclear Waste Isolation, Columbus, OH (1979).

12. T. Harvey, R. A. Heckman, D. F. Towse, D. Isherwood, T. Holdsworth, Site Suitabilitu Criteria for Solidified High Level Waste Repositories, Lawrence Livermore National Laboratory, Livırmore, CA, UCRL-52633 (1977).

13. Arthur D. Littie, Inc., Assessment of Accidental Pathurays, Draft Subtask D Report, Vol. I, C-80560 (1978).

14. N. A. Boriner, and Y. C. Ng, Biodose: A Code for Predicting the Dose to Man from Radionuclides Released from Underground Nuclear Waste Repositories, Law'rence Livermore National Laboratory, Livermore, CA, UCID-18652, (1980).

15. "Limits for Intakes of Radionuclides by Workers," International Commission on Radiological Protection, ICRP-30 (Pergamon Press, NY, 1978).

16. M. S. Giuffre, M. F. Kaplan, D. A. Ensminger, S. G. Oston, J. Y. Nalbandian, Bedded Salt Repository Analysis: Final Report, Lawrence Livermore National Laboratory, Livermore, CA, UCRL-15236 (1980).

17. H. Cheung, L. Edwards, T. Harvey, and M. Revelli, Nuclear Waste Form Assesment for U.S. Dejense Waste at Savannah River Plant, Annual Report, Fiscal Year 1982, Lawrence Livermore National Laboratory, Livermore, CA, UCRL-53189-82 (1982).

18. J. H. Campbell, SYNROC: Permanent Radioactive-Waste Storage, Energy and Technology Review, Lawrence Livermore National Laboratory, Livermore, CA (Dec. 1981).

19. Third Report: Development of Site Suitability and Design Performance Data Base for a High Lerel Nuclear Waste Repository for Lawrence Livermore Laboratory (Golder Associates, Kirkland, W'A), Lawrence Livermore National Laboratory, Livermore, CA, UCRL-13856 (1978).

20. H. C. Burkholder, "The Development of Release Scenarios for Geologic Nuclear Waste Repositories: Where Have We Been? Where Should We Be Going," Procecdings of the NEA Worksinop, Paris (September 1980) pp. 13-26. 